\title{
Fatigue in Multiple Sclerosis: Neural Correlates and the Role of Non-Invasive Brain Stimulation
}

\author{
Moussa A. Chalah ${ }^{1,2}$, Naji Riachi ${ }^{3}$, Rechdi Ahdab ${ }^{1,3}$, Alain Créange ${ }^{1,4}$, \\ Jean-Pascal Lefaucheur ${ }^{1,2}$ and Samar S. Ayache ${ }^{1,2 *}$ \\ ${ }^{1}$ EA 4391, Excitabilité Nerveuse et Thérapeutique, Université Paris-Est-Créteil, Créteil, France, ${ }^{2}$ Service de Physiologie - \\ Explorations Fonctionnelles, Hôpital Henri Mondor, Assistance Publique - Hôpitaux de Paris, Créteil, France, ${ }^{3}$ Neurology \\ Division, University Medical Center Rizk Hospital, Beirut, Lebanon, ${ }^{4}$ Service de Neurologie, Hôpital Henri Mondor, Assistance \\ Publique - Hôpitaux de Paris, Créteil, France
}

OPEN ACCESS

Edited by:

Surjo R. Soekadar.

Department of Psychiatry and

Psychotherapy, Germany

Reviewed by:

Andrew Chan,

Ruhr University Bochum, Germany Robert Weissert,

University of Regensburg, Germany

*Correspondence:

Samar S. Ayache samarayache@gmail.com

Received: 30 May 2015 Accepted: 11 November 2015 Published: 30 November 2015

Citation:

Chalah MA, Riachi N, Ahdab R,

Créange A, Lefaucheur J-P and Ayache SS (2015) Fatigue in Multiple Sclerosis: Neural Correlates and the

Role of Non-Invasive Brain

Stimulation.

Front. Cell. Neurosci. 9:460.

doi: 10.3389/fncel.2015.00460
Multiple sclerosis (MS) is a chronic progressive inflammatory disease of the central nervous system (CNS) and the major cause of non-traumatic disability in young adults. Fatigue is a frequent symptom reported by the majority of MS patients during their disease course and drastically affects their quality of life. Despite its significant prevalence and impact, the underlying pathophysiological mechanisms are not well elucidated. MS fatigue is still considered the result of multifactorial and complex constellations, and is commonly classified into "primary" fatigue related to the pathological changes of the disease itself, and "secondary" fatigue attributed to mimicking symptoms, comorbid sleep and mood disorders, and medications side effects. Radiological, physiological, and endocrine data have raised hypotheses regarding the origin of this symptom, some of which have succeeded in identifying an association between MS fatigue and structural or functional abnormalities within various brain networks. Hence, the aim of this work is to reappraise the neural correlates of MS fatigue and to discuss the rationale for the emergent use of noninvasive brain stimulation (NIBS) techniques as potential treatments. This will include a presentation of the various NIBS modalities and a suggestion of their potential mechanisms of action in this context. Specific issues related to the value of transcranial direct current stimulation (tDCS) will be addressed.

\section{Keywords: multiple sclerosis, fatigue, tDCS, non-invasive brain stimulation, network}

\section{INTRODUCTION}

Multiple sclerosis (MS) is a chronic progressive inflammatory disease of the central nervous system (CNS) and represents the major cause of non-traumatic disability in young adults (Noseworthy et al., 2000; Compston and Coles, 2008). Its estimated prevalence in Europe is 83 per 100,000, with rates being approximately twice as high for women as for men and lower in the southern than in the northern European countries (Pugliatti et al., 2006).

The precise etiology of MS remains obscure and involves a plethora of mechanisms. Its clinical course is highly heterogeneous, during which patients may develop various motor, sensory, cognitive, and behavioral symptoms. The available treatments consist of the disease-modifying therapies (such as the immunosuppressants, immunomodulators, and monoclonal antibodies) (Wingerchuk and Carter, 2014); in addition to several symptomatic treatments that are usually prescribed to control disorders of strength, sensation, mood, sleep, etc. 
Among the frequently encountered symptoms in MS, fatigue remains the most challenging one, majorly altering the quality of life (Krupp et al., 1988; Janardhan and Bakshi, 2002; Merkelbach et al., 2002; Giovannoni, 2006; Induruwa et al., 2012). Indeed, it affects up to $75 \%$ of MS patients at some point in their disease course (Bakshi et al., 2000; Lerdal et al., 2007; Kos et al., 2008), gets exacerbated during the day (Comi et al., 2001; Morris et al., 2002; Mills and Young, 2008; Krupp et al., 2010), and increases with hot and humid environment (Bakshi, 2003; Bol et al., 2012; Leavitt et al., 2012).

Although fatigue is reported by the majority of individuals as their most common and disabling symptom (Krupp et al., 1989, 2010; Fisk et al., 1994a,b; Colosimo et al., 1995; Bakshi, 2003; Lobentanz et al., 2004; Flensner et al., 2008), no clear definition exists in the literature; which makes it at a time hard to be described by patients and diagnosed by physicians. Such a difficulty is further exacerbated by the diversity of the fatigue assessment tools employed by scientists and researchers. In the majority of cases, fatigue is self-reported using various subjective scales, like Fatigue Severity Scale (FSS) or Modified Fatigue Impact Scale (MFIS), among others.

From an etiological perspective, no single mechanism accounts for its occurrence, and MS fatigue is rather seen as a complex and multifactorial constellation (Bakshi, 2003; MacAllister and Krupp, 2005; Kos et al., 2008; Braley and Chervin, 2010; Krupp et al., 2010; Vucic et al., 2010; Induruwa et al., 2012). In an attempt to account for its origin, many hypotheses have been raised and include the processes of demyelination and axonal loss that involve various cortical and subcortical regions; the neuroimmune dysregulation supported by the elevated levels of cytokines and other inflammatory mediators encountered in MS patients; and the neuroendocrine dysfunction along the hypothalamo-pituitary-adrenal (HPA) axis, among others.

Facing this reality, various pharmacological (dopaminergic drugs, psychostimulants, etc.) and alternative interventions (aerobic exercises, cooling therapies, psychotherapies, etc.) have been tried but only resulted in limited benefits (Vucic et al., 2010; Induruwa et al., 2012). Nowadays, non-invasive brain stimulation (NIBS) techniques have gained an important interest in the treatment of many neuropsychiatric disorders; hence, they might be of some help in terms of MS fatigue.

In this review, we will first revisit the definition of this symptom, summarize its various types, and shed the light on the central fatigue encountered in MS patients; a particular emphasis will be given to the available data regarding the proposed fatigue networks. A final part will be dedicated to the NIBS techniques and their possible mechanisms in this context. The pharmacological and other alternative therapies are beyond the scope of this work (For reviews see Vucic et al., 2010; Induruwa et al., 2012).

\section{MULTIPLE SCLEROSIS FATIGUE}

To start, the definition of fatigue differs widely among patients, researchers, and physicians. From the patients' perspective, fatigue is usually reported as "excessive tiredness," "malaise," or "weakness" (Krupp, 2003). As for researchers and physicians, the definition varied among the available data. For instance, Wessely observed the fatigue in terms of its origin and referred to it as having its source at the level of the upper motor neuron or above (Wessely, 1998). Gandevia et al. defined it as a progressive exercise-induced reduction in voluntary activation of a muscle (Gandevia, 2001). Chaudhuri and Behan considered it a failure to initiate and/or sustain attention tasks and physical activities requiring self-motivation in the absence or not related to physical or cognitive dysfunction (Chaudhuri and Behan, 2000). Other authors described it as a subjective lack of physical and/or mental energy (Benedict et al., 2005). Interestingly, a medical definition of fatigue was proposed in one study which consisted of a qualitative phase followed by a cross-sectional questionnaire survey in 40 MS patients (Mills and Young, 2008). Here, the symptom was defined as a reversible motor and cognitive impairment, with a reduced motivation and an increased desire to rest. It can occur either spontaneously or following various factors such as mental or physical activity, humidity, infections, and food ingestion.

Second, fatigue encountered in MS patients is commonly classified into a "primary" fatigue related to the CNS pathological changes in the context of the disease itself; and a "secondary" fatigue attributed to MS-related comorbidities. This includes weakness that can mimic fatigue (van der Werf et al., 1998), mood and sleep disorders (Möller et al., 1994; Induruwa et al., 2012), and medications side effects (Braley and Chervin, 2010). It is noteworthy that disease-modifying therapies themselves could have some impact on MS fatigue. For instance, MS patients treated with Interferon-beta can experience fatigue (Braley and Chervin, 2010). Conversely, the monoclonal antibody Natalizumab could reduce fatigue, as shown in TYNERGY trial (For reviews see Hoepner et al., 2014).

Primary fatigue results from a spectrum where one pole is the inability to generate the force required to perform the task due to a failure of force production at the muscle level ("peripheral fatigue"); and the other pole is the inability to sustain the required neural drive to muscle because of supraspinal, spinal, and even peripheral nerve contribution ("central fatigue") (Gandevia, 2001; Zwarts et al., 2008). Interestingly, "central fatigue" can be the result of both cognitive and physical exertion (Claros-Salinas et al., 2013) and can reflect either a subjective sensation (fatigue) or an objective change in performance (fatigability) (Kluger et al., 2013).

Another way to perceive MS fatigue consists of differentiating "trait" from "state" fatigue. The "trait" fatigue was the focus of several papers and was defined as a stable state that expresses the global status of patients, which does not significantly change over time, and usually assessed with fatigue scales (Sepulcre et al., 2009; Calabrese et al., 2010; Genova et al., 2013). In contrast, "state" fatigue was the subject of few works only; it is a transient condition characterized by a decreased performance during an acute but sustained effort (DeLuca et al., 2008; Genova et al., 2013). In addition, it can fluctuate in response to external and internal factors, and is usually tested during task performance. 


\section{MS FATIGUE, DISABILITY, AND DISEASE DURATION}

Most of the studies that investigated MS fatigue aimed to understand the contributory role of clinical, demographic and neuroimaging data. In this perspective, conflicting data were found regarding the relationship between fatigue severity and the level of physical disability. Although many studies have established a positive correlation between fatigue scores and the degree of physical disability based on the Expanded Disability Status Scale (EDSS) (Colosimo et al., 1995; van der Werf et al., 1998; Flachenecker et al., 2002; Niepel et al., 2006; Pellicano et al., 2010), others have either found a weak association (Ford et al., 1998; Pittion-Vouyovitch et al., 2006; Yaldizli et al., 2011), or failed to detect any relationship (Krupp et al., 1988; Roelcke et al., 1997; Sheean et al., 1997; Provinciali et al., 1999; Rocca et al., 2009; Cruz Gómez et al., 2013; Derache et al., 2013; Gobbi et al., 2014a; Hesse et al., 2014). Such findings might be related to the multi-component aspect of this symptom and/or the differences among these studies in terms of sample size, recruited MS subtypes, EDSS cut-offs, and the subjective tools used for reporting fatigue. Furthermore, the majority of the studies could not correlate fatigue scores with disease duration (Roelcke et al., 1997; Bakshi et al., 1999; Niepel et al., 2006; Pellicano et al., 2010; Gold et al., 2011; Yaldizli et al., 2011; Derache et al., 2013).

Admitting this apparent occurrence of fatigue independently from disease duration and disability progression, there is a growing interest in understanding the radiological and neurophysiological underpinnings of MS fatigue.

\section{NEURAL CORRELATES OF MS FATIGUE}

\section{Impact of White Matter and Gray Matter Abnormalities}

Magnetic resonance imaging (MRI) studies revealed controversial data regarding the relationship between fatigue severity and each of the brain atrophy and lesion load. While some studies of them have yielded positive associations, others failed to detect any relationship. The latter finding may be attributed in part to the small sample size selected in some of these studies, and to the cross-sectional or short-term longitudinal follow up design adopted by most of them. A summary is available in Table $\mathbf{1}$.

Interestingly, a large number of works have succeeded in establishing a link between fatigue scores and gray matter (GM) and white matter (WM) abnormalities in specific cortical and subcortical regions that were proposed to be major components of the MS fatigue networks. Such networks will constitute the main scope of this section.

\section{Anatomical Correlates of MS Fatigue The Fronto-striatal Network}

Among the early evidences of cortico-subcortical circuit dysfunction as a substrate for MS fatigue, the involvement of a "fronto-striatal network" was highlighted by two studies. In the first one, fatigued MS (F-MS) patients had a predominant reduced cerebral metabolic rate of glucose in the frontal lobe and basal ganglia (Roelcke et al., 1997); FSS scores were inversely correlated with such a rate in the right dorsolateral prefrontal cortex (DLPFC). In line with these results, Pardini et al. reported a significant association between MFIS scores and a cluster of voxels located in the left frontal WM, which was further found to be involved in the fronto-striatal network, among others (Pardini et al., 2010). In a third study, MS patients underwent functional MRI (fMRI) during the performance of a single motor task using the right hand (Specogna et al., 2012). Compared to non-fatigued MS (NF-MS) patients, F-MS patients had a greater activation of the premotor area ipsilateral to the movement, the right putamen, and the right DLPFC. Conversely, Codella et al. failed to demonstrate a difference in fronto-striatal GM pathology between F-MS and NF-MS patients, or a correlation between such findings and FSS scores. These results could be partially attributed to the small sample size (Codella et al., 2002b). Table 2 provides a summary of the abovementioned studies.

\section{The Parieto-striatal Network}

A parieto-striatal network was the object of one MRI study involving $15 \mathrm{~F}-\mathrm{MS}$ and $15 \mathrm{NF}-\mathrm{MS}$ patients. A significant association was found between fatigue scores and the lesion load in the parietal lobe, internal capsule, and periventricular trigone, emphasizing the role of this network in MS fatigue (Colombo et al., 2000).

\section{Deep Gray Matter Substrates}

A group of authors correlated MS fatigue with isolated deep GM pathologies. One study assessed the involvement of caudate, putamen, and thalamus based on the mean $\mathrm{T} 1$ relaxation time (Niepel et al., 2006), an MRI parameter previously found to correlate with the degree of disability in MS patients (Parry et al., 2002). Compared to their non-fatigued counterparts, FMS patients had significantly higher median T1 values in the thalami, which were significantly correlated to FSS scores. The thalamic nuclei represent an essential relay center in information integration, the dysfunction of which might contribute to fatigue. Another work employed the proton magnetic resonance spectroscopy to study the relationship between fatigue scores and the $\mathrm{N}$-acetyl aspartate to creatinine ratio (NAA/cr), a neural marker of axonal damage, within the frontal cortex and basal ganglia (Téllez et al., 2008). A correlation was only found between the physical domain of MFIS and NAA/cr within the lentiform nucleus complex. A third study assessed the perfusion parameters of deep GM and MS fatigue based on the multidimensional fatigue inventory (MFI) (Inglese et al., 2007). An association was found between MFI scores and the cerebral blood volume and flow in the thalamus and basal ganglia (for a summary, see Table 3).

It is important to note that the difference in the fatigue scales among these three studies might be behind the minor variation in the results. In fact, the 7-item FSS has some limitations due to its classic ordinal construct (Krupp et al., 1988); the 21-item MFIS is a modified version of the original fatigue impact scale (FIS) that explores the physical, psychosocial and cognitive domains of fatigue (Fisk et al., 1994a,b); and the 20-item MFI employed in the 
TABLE 1 | Studies evaluating the role of gray and white matter abnormalities in multiple sclerosis fatigue.

\begin{tabular}{|c|c|c|c|c|c|}
\hline Authors (Year) & Technique & Parameter (s) & Scale & Population & Correlation with fatigue \\
\hline \multirow[t]{2}{*}{ van der Werf et al., 1998} & MRI & Lesion load & CIS-Fatigue scale & $45 \mathrm{MS}$ & No \\
\hline & & Brain atrophy & & & \\
\hline \multirow[t]{2}{*}{ Bakshi et al., 1999} & MRI & Lesion load & FSS & $71 \mathrm{MS}$ & No \\
\hline & & Brain atrophy & & & \\
\hline Mainero et al., 1999 & MRI & Gd-enhancing lesions & FSS & $11 \mathrm{MS}$ & No \\
\hline Codella et al., 2002a & MRI (MTI, DTI) & Quantification of lesions and NABT & FSS & $28 \mathrm{MS}$ & No \\
\hline Tartaglia et al., 2004 & MRS & Axonal damage & FSS & $73 \mathrm{MS}$ & Yes \\
\hline Marrie et al., 2005 & $\mathrm{BPF}$ & Brain atrophy & SIPSR & $134 \mathrm{MS}$ & Yes \\
\hline \multirow[t]{2}{*}{ Tedeschi et al., 2007} & MRI & Lesion load & FSS & $222 \mathrm{MS}$ & Yes \\
\hline & & WM and GM atrophy & & & \\
\hline \multirow[t]{3}{*}{ Papadopoulou et al., 2013} & MRI & GM volume & FSMC & $91 \mathrm{MS}$ & No \\
\hline & & Cortical volume & & & \\
\hline & & WM lesions & & & \\
\hline \multirow[t]{2}{*}{ Gobbi et al., 2014a } & MRI & GM and WM atrophy & FSS & $123 \mathrm{MS}$ & No \\
\hline & & Lesions distribution & & & \\
\hline
\end{tabular}

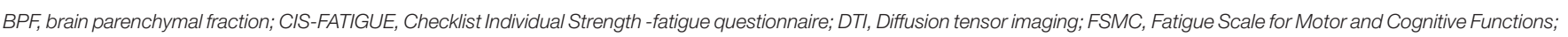

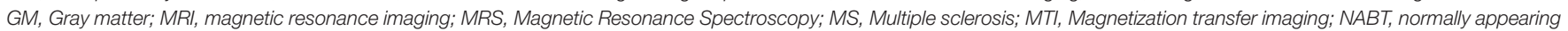
brain tissues; SIPSR, Sickness Impact Profile's Sleep and Rest Scale; WM, white matter.

\section{TABLE 2 | Studies evaluating the role of fronto-striatal networks in multiple sclerosis fatigue.}

\begin{tabular}{|c|c|c|c|c|}
\hline Authors (Year) & Technique & Scales & Population & Outcome \\
\hline Roelcke et al., 1997 & PET & FSS & $35 \mathrm{MS}$ & Significant correlation between FSS and glucose reduction in the right DLPFC \\
\hline Pardini et al., 2010 & MRI (DTI) & MFIS & 40 RRMS & $\begin{array}{l}\text { Significant correlation between MFIS scores and deep left frontal WM, a } \\
\text { region found to be involved in fronto-striatal networks, among others }\end{array}$ \\
\hline Specogna et al., 2012 & fMRI (+single motor task) & FSS & 24 RRMS & $\begin{array}{l}\text { Significant correlation between FSS scores and activation patterns of the } \\
\text { premotor area }\end{array}$ \\
\hline
\end{tabular}

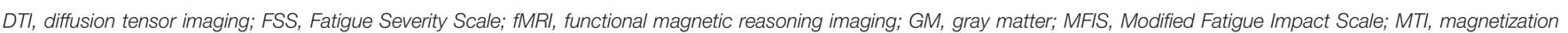
transfer imaging; PET, Positron Emission Tomography; PMC, premotor cortex; RRMS, relapsing remitting multiple sclerosis; WM, white matter; SMA, supplementary motor area.

\section{TABLE 3 | Studies supporting the role of deep gray matter substrates in multiple sclerosis fatigue.}

\begin{tabular}{|c|c|c|c|c|}
\hline Authors (Year) & Technique & Scales & Population & Outcome \\
\hline Niepel et al., 2006 & MRI & FSS & 52 RRMS & Correlation of FSS with abnormal T1 relaxation time within the thalami \\
\hline Inglese et al., 2007 & MRI & MFI & 22 MS (11RRMS, 11 PPMS) & $\begin{array}{l}\text { Correlation of MFI with the cerebral blood volume and flow in the thalamus } \\
\text { and basal ganglia }\end{array}$ \\
\hline Téllez et al., 2008 & ${ }^{1} \mathrm{H}-\mathrm{MRS}$ & MFIS, FSS & 41 RRMS & $\begin{array}{l}\text { Correlation of physical domain of MFIS with abnormal NAA/cr ratio within the } \\
\text { lentiform nucleus }\end{array}$ \\
\hline
\end{tabular}

FSS, Fatigue Severity Scale; ${ }^{1}$ H-MRS, proton magnetic reasoning imaging; MFI, Multidimensional Fatigue Inventory; MFIS, Modified Fatigue Impact Scale; NAA/cr, N-acetyl aspartate to creatinine ratio; RRMS, relapsing remitting multiple sclerosis; PPMS, primary progressive MS.

last study evaluates five fatigue dimensions, namely the general, physical and mental fatigue along with the reduced motivation and activity (Smets et al., 1995).

\section{Cortico-cortical Networks}

Among the works dedicated to MS fatigue, some attention was paid on the pathological changes affecting the corticocortical networks, particularly those involving the frontal and parietal cortices. In this setting, six studies were found to fulfill these criteria. In one study, electroencephalography (EEG) recording were performed during and following the performance of a simple motor task (Leocani et al., 2001). Compared to NF-MS patients and healthy controls, F-MS patients had higher event-related desynchronization (ERD) over the midline frontal structures during the movement and lower eventrelated synchronization (ERS) in the contralateral central area after the movement (Leocani et al., 2001). These are the respective markers of cortical activation and idling. Therefore, this altered balance between excitation (ERD) and inhibition (ERS) might result from axonal damage and the subsequent 
loss of functional intra-cortical connections. The post-movement loss of inhibition (ERS) seems to trigger brain activation and might account for MS fatigue. Tartaglia et al. found that, during the performance of a fatiguing cognitive task, MS patients exhibited an altered pattern of activation within the left primary sensory and premotor cortices and the supplementary motor area, despite the lack of performance difference in comparison to the healthy group (Tartaglia et al., 2008). In another study, fatigue was significantly correlated with frontal GM atrophy especially involving the superior frontal gyrus (SFG) on the left and the middle frontal gyrus (MFG) bilaterally, and with lesion load namely found within the left frontal and right parieto-temporal areas (Sepulcre et al., 2009). In addition, using DTI-based tractography, one study established a correlation between fatigue scores and a significant cluster of voxels in the deep WM involving fronto-frontal fibers, among others (Pardini et al., 2010). It is noteworthy that fatigue scores were frequently found to correlate with isolated regional metabolic changes in the posterior parietal cortex (PPC) (Pellicano et al., 2010), left precentral gyrus (Riccitelli et al., 2011), bilateral frontal cortices (Huolman et al., 2011), left superior frontal and right inferior temporal gyri (Rocca et al., 2014), and left supplementary motor area (Cruz Gómez et al., 2013). Other studies reported an association between fatigue and abnormalities involving the corpus callosum and its radiating fibers that primarily ensure the interhemispheric cortico-cortical connections (Yaldizli et al., 2011, 2014; Gobbi et al., 2014b; Rocca et al., 2014). The above-mentioned papers are summarized in Table 4.

\section{The Cortico-striato-thalamo-cortical Loop}

Considering this bunch of evidence involving various brain areas and admitting the heterogeneous nature of MS, a large neural network should be considered in the context of MS fatigue.

First, using morphological MRI, one study has found that FMS patients had atrophy in the striatum, thalamus, SFG, and intraparietal gyrus (IPG). Correlations were observed between MFIS cognitive subscale and each of the striatal volume, and the cortical thickness of the PPC and the MFG. The MFIS physical subscale was also correlated with the striatal volume and SFG cortical thickness (Calabrese et al., 2010). Andreasen et al. used DTI and magnetization transfer imaging to study the central motor drive during isometric contraction (Andreasen et al., 2010). They found that F-MS patients had regional atrophy in the DLPFC, PPC, and basal ganglia. However, no correlation was found between these atrophies and FSS scores, a finding that might be attributed to the small sample.

Data from fMRI studies have documented an altered pattern of regional activation and functional connectivity (FC) in FMS patients at rest or during the performance of fatiguing motor and cognitive tasks. In one study, F-MS patients showed hypoactivation within the ipsilateral rolandic operculum and precuneus, as well as the contralateral thalamus and MFG. FSS scores were inversely correlated with the activation pattern of the contralateral thalamus and the ispsilateral rolandic operculum (Filippi et al., 2002). A second work compared the brain activation pattern of fatigable and non-fatigable MS patients following interferon injection (Rocca et al., 2007). Following the injection, fatigable patients showed increased activation

TABLE 4 | Studies highlighting the impact of cortico-cortical connections in multiple sclerosis fatigue.

\begin{tabular}{|c|c|c|c|c|}
\hline Authors (Year) & Technique & Scales & Population & Outcome \\
\hline Leocani et al., 2001 & EEG (during simple motor task) & FSS & $23 \mathrm{MS}$ & $\begin{array}{l}\text { Correlation of fatigue scores with ERD over the midline frontal structures } \\
\text { during movement, and an inverse correlation of those scores with } \\
\text { contralateral central ERS post-movement }\end{array}$ \\
\hline Tartaglia et al., 2008 & fMRI (during PASAT) & FSS & 10 RRMS & $\begin{array}{l}\text { Correlation between fatigue scores and an altered activation pattern } \\
\text { within sensory and motor areas }\end{array}$ \\
\hline Sepulcre et al., 2009 & MRI & MFIS & $60 \mathrm{MS}$ & Correlation between fatigue scores and fronto-parietal pathologies \\
\hline Pardini et al., 2010 & MRI & MFIS & 40 RRMS & $\begin{array}{l}\text { Correlation between MFIS scores and deep left frontal WM, a region } \\
\text { found to be involved in fronto-frontal and fronto-occipital networks }\end{array}$ \\
\hline \multirow[t]{2}{*}{ Pellicano et al., 2010} & MRI & MFIS & 20 RRMS & Correlation of fatigue scores with posterior parietal cortical thickness \\
\hline & & & 4 SPMS & \\
\hline Yaldizli et al., 2011 & $\mathrm{MRI}$ & FSS & 70 RRMS & Association between fatigue scores and CC atrophy \\
\hline Huolman et al., 2011 & fMRI (during mPVSAT) & - & $15 \mathrm{MS}$ & Hyperactivation of bilateral frontal regions \\
\hline Riccitelli et al., 2011 & $\mathrm{MRI}$ & FSS & 24 RRMS & $\begin{array}{l}\text { Correlation between fatigue scores and GM atrophy within the left } \\
\text { precentral gyrus }\end{array}$ \\
\hline Cruz Gómez et al., 2013 & $\mathrm{fMRI}$ & FSS & 60 RRMS & $\begin{array}{l}\text { Correlation between fatigue scores and WM atrophy within the left } \\
\text { supplementary motor areas }\end{array}$ \\
\hline Rocca et al., 2014 & MRI & FSS & $63 \mathrm{MS}$ & $\begin{array}{l}\text { Correlations between fatigue scores and atrophy of the right inferior } \\
\text { temporal gyrus, left superior frontal gyrus, and forceps major }\end{array}$ \\
\hline Yaldizli et al., 2014 & MRI & FSS & $113 \mathrm{MS}$ & Association between fatigue scores and CC atrophy \\
\hline Gobbi et al., 2014b & MRI & MFIS & $147 \mathrm{MS}$ & Association between fatigue and CC pathology \\
\hline
\end{tabular}

CC, Corpus callosum; EEG, electroencephalography; ERD, event related desynchronization; ERS, event related synchronization; F, fatigued; FSS, Fatigue Severity Scale, fMRI, functional magnetic resonance imaging, GM, gray matter; HCS, Healthy controls; MFIS, Modified Fatigue Impact Scale; mPVSAT, modified Paced Visual Serial Addition Test; PASAT, Paced Auditory Serial Addition Test; RRMS, relapsing remitting multiple sclerosis; SPMS, secondary progressive multiple sclerosis; WM, white matter. 
of the basal ganglia, thalami, primary sensorimotor cortex, supplementary motor area, and several frontal regions. In a third study, kinematic and fMRI data were obtained from healthy controls, F-MS and NF-MS patients. Compared to the other groups, F-MS patients had an increased activation of the left secondary somatosensory cortex and the right precuneus and decreased activation of the right thalamus, right basal ganglia, left inferior frontal gyrus (IFG) during in-phase and anti-phase movements (Rocca et al., 2009). Here, the fatigue effect was mainly located in fronto-parietal regions including the left IFG, and left postcentral gyrus, among others. A fourth study found an association between mental fatigue and hyperactivation in the fronto-parietal regions, basal ganglia, and thalamus (DeLuca et al., 2008).

It is worth noting that two other works focused on the brain activation patterns and FC during the performance of a mentally fatiguing cognitive task. In the first study, MS patients had stronger cortico-cortical and subcortico-subcortical FC and weaker cortico-subcortical FC between the left PPC and the right caudate head compared to healthy controls (Engström et al., 2013). Here, MS fatigue was significantly correlated with the right substantia nigra ( $\mathrm{SN}$ ) activation and marginally with the left PPC activation; the reported activation pattern within the SN might have increased the thalamic inhibition and accounted for MS fatigue. In the other study, MS patients had hyperactivation of the caudate nucleus which was associated with state fatigue (Genova et al., 2013). In the same work, the authors used DTI and demonstrated a correlation between FSS scores and reduced fraction anisotropy (FA) in the anterior internal capsule, a structure having connections with the caudate nucleus and the thalamus. These findings support the role of the "striatalthalamic-frontal” system in MS fatigue (Genova et al., 2013).

In addition, Derache et al. found that their F-MS cohort had a significant reduction of GM density in clusters, some of which are located in the bilateral frontal cortex and in the left parietal cortex. Fatigue scores were negatively correlated with each of GM density in the same involved fronto-parietal areas, the GM density in bilateral thalamus and the rest central glucose metabolic rate within the basal ganglia (Derache et al., 2013). Finally, in a resting-state (rs) fMRI study conducted by Finke et al. fatigue severity was negatively correlated with the FC between the basal ganglia and the medial prefrontal gyrus (PFG), precuneus, and posterior cingulate cortex; and positively with the FC between the caudate nucleus and the motor cortex (Finke et al., 2014).

To sum up, these studies altogether support the existence of a cortico-striato-thalamo-cortical loop as a neural correlate of MS fatigue. The latter seems to englobe motor and nonmotor circuits acting together to induce the symptom in question (Table 5).

\section{Other Neural Correlates}

Apart from the above-discussed circuits, a number of reports have linked MS fatigue to other cerebral structures. For instance, one study has found an association between MS fatigue and an altered integrity of the fibers that connect the posterior hypothalamus and the mesencephalon (Hanken et al., 2015). This was in line with two previous works. In the first one, F-MS patients exhibited a higher activity of the HPA axis than those without fatigue (Gottschalk et al., 2005). As for the second one, FSS scores were positively correlated with the T1 relaxation time values within the hypothalamus of MS patients (Zellini et al., 2009).

To note, other neural correlates were associated with fatigue, and include the cerebellum (Roelcke et al., 1997; Filippi et al., 2002; Rocca et al., 2009), the cingulate cortex (Roelcke et al., 1997; Filippi et al., 2002; Rocca et al., 2007; Tartaglia et al., 2008; Sepulcre et al., 2009; Andreasen et al., 2010; Finke et al., 2014; Pardini et al., 2015), the right anterior thalamic radiations (Bester et al., 2013; Gobbi et al., 2014b; Rocca et al., 2014), and the nucleus accumbens (Rocca et al., 2014), among others.

\section{Neuro-immune Correlates of MS Fatigue}

Immunological factors have long been recognized as key factors in the pathophysiology of MS (Rovaris et al., 1996; Khademi et al., 2000; Baraczka et al., 2003). Hence, several studies have looked at the potential role of the inflammatory cytokines in MS fatigue. Interestingly, a significant correlation was found between the level of response to Amantadine and Pemoline pharmacological treatments of fatigue- and the reduction in serum levels of interleukin 1-beta (IL-1 $\beta$ ) and interleukin 6 (IL-6) in MS patients (Bertolone et al., 1993). Furthermore, the median levels of tumor necrosis factor alpha (TNF- $\alpha$ ) mRNA expression and the serum levels of TNF- $\alpha$ and interferon gamma (IFN- $\gamma$ ) were found to be significantly higher in F-MS patients than in NF ones (Flachenecker et al., 2004; Heesen et al., 2006; PokryszkoDragan et al., 2012). Additionally, a positive relationship was found between IL-6 serum levels and fatigue scores in MS patients (Malekzadeh et al., 2015). Moreover, a higher frequency of cytokine producing CD8+ T cells was found among MS patients and was the only significant predictor of fatigue scores (Gold et al., 2011).

All these studies hint toward the role of inflammation in inducing MS fatigue, which might be of potential interest for future targeted therapies.

\section{NIBS AND MS FATIGUE}

Various pharmacological and non-pharmacological interventions have been tried to treat MS fatigue, but showed limited benefits and multiple side effects (Induruwa et al., 2012; Khan et al., 2014). As discussed above, neuroimaging studies have focused on the neural network changes underlying MS fatigue. Hence, acting on these networks could be of particular help in the management of such a debilitating symptom, and thereby would support the use of NIBS in this context.

\section{NIBS Principles}

There is a growing interest in studying the therapeutic effects of NIBS techniques in neurological or psychiatric diseases (Lefaucheur et al., 2014). These techniques include repetitive transcranial magnetic stimulation (rTMS) and transcranial direct current stimulation (tDCS). 
TABLE 5 | Studies highlighting the role of the cortico-striato-thalamo-cortical loop of fatigue in multiple sclerosis.

\begin{tabular}{|c|c|c|c|c|}
\hline Authors (Year) & Technique & Scales & Population & Outcome \\
\hline Filippi et al., 2002 & fMRI (during simple motor task) & FSS & $29 \mathrm{MS}$ & $\begin{array}{l}\text { Inverse correlation of FSS scores with the activation pattern of the } \\
\text { contralateral thalamus and the ipsilateral rolandic operculum }\end{array}$ \\
\hline Rocca et al., 2007 & $\begin{array}{l}\text { fMRI (during simple motor task, } \\
\text { before and after IFN injection) }\end{array}$ & FSS & $22 \mathrm{MS}$ & $\begin{array}{l}\text { Post-injection fatigable patients showed increased activations of the } \\
\text { basal ganglia, thalami, primary sensorimotor cortex, SMA, and several } \\
\text { frontal regions }\end{array}$ \\
\hline DeLuca et al., 2008 & fMRI (during mSDMT) & $\mathrm{N} / \mathrm{A}$ & $12 \mathrm{MS}$ & $\begin{array}{l}\text { Association between mental fatigue and hyperactivation within the } \\
\text { fronto-parietal regions, basal ganglia, and thalamus }\end{array}$ \\
\hline Rocca et al., 2009 & $\begin{array}{l}\text { MRI, fMRI (during kinematic } \\
\text { movement) }\end{array}$ & FSS & 24 RRMS & $\begin{array}{l}\text { Association between fatigue and the activation pattern of the } \\
\text { fronto-parietal regions including the left IFG and left postcentral gyrus, } \\
\text { among others }\end{array}$ \\
\hline Andreasen et al., 2010 & $\begin{array}{l}\mathrm{MRI} \text { (during isometric } \\
\text { contraction) }\end{array}$ & FSS & $34 \mathrm{MS}$ & $\begin{array}{l}\text { No correlation between FSS scores and the atrophy found within the } \\
\text { DLPFC, PPC, and basal ganglia }\end{array}$ \\
\hline \multirow[t]{2}{*}{ Calabrese et al., 2010} & MRI & FSS/MFIS & 152 RRMS & $\begin{array}{l}\text { Correlation of cognitive MFIS scores with striatal volume and the cortical } \\
\text { thickness of PPC and MFG }\end{array}$ \\
\hline & & & & $\begin{array}{l}\text { Correlation of physical MFIS scores with striatal volume and the cortical } \\
\text { thickness of SFG }\end{array}$ \\
\hline Engström et al., 2013 & $\begin{array}{l}\text { fMRI (during a complex cognitive } \\
\text { task) }\end{array}$ & FIS & $15 \mathrm{MS}$ & Correlation of fatigue with right substansia nigra hyperactivation \\
\hline Derache et al., 2013 & PET/MRI & MFIS & 17 RRMS & $\begin{array}{l}\text { Negative correlation between fatigue scores and clusters of reduced GM } \\
\text { density within the fronto-parietal cortices and the thalami; and with the } \\
\text { rest cerebral glucose metabolic rate of the basal ganglia }\end{array}$ \\
\hline \multirow[t]{2}{*}{ Genova et al., 2013} & $\begin{array}{l}\text { fMRI (during a sustained } \\
\text { cognitive task) }\end{array}$ & VAS & $12 \mathrm{MS}$ & Association of state fatigue with caudate nucleus hyperactivation \\
\hline & MRI (DTI) & FSS & $13 \mathrm{MS}$ & $\begin{array}{l}\text { Correlation between FSS scores and the reduced fraction anisotropy in } \\
\text { the anterior internal capsule }\end{array}$ \\
\hline \multirow[t]{2}{*}{ Finke et al., 2014} & MRI, fMRI & FSS & 44 RRMS & $\begin{array}{l}\text { Negative correlation between fatigue severity and rc-FC of basal ganglia } \\
\text { and medial PFG, precuneus, posterior cingulate cortex }\end{array}$ \\
\hline & & & & $\begin{array}{l}\text { Positive correlation between fatigue severity and rs-FC of caudate and } \\
\text { motor cortex }\end{array}$ \\
\hline
\end{tabular}

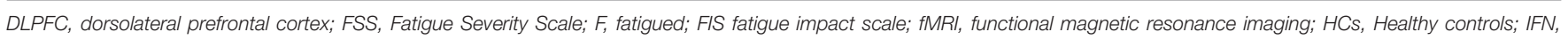

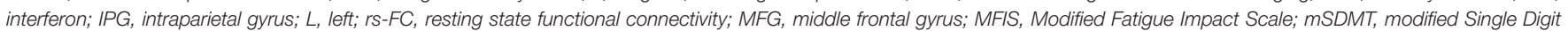

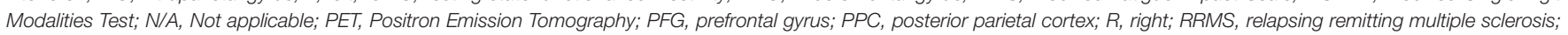
SFG, superior frontal gyrus; SMA, supplementary motor area; VAS, Visual Analog Scale.

rTMS consists of a transcranial delivery of an electromagnetic field via a stimulation coil localized on the patient's scalp. This results in an intracortical current that is strong enough to trigger action potentials (APs) (Lefaucheur, 2012). rTMS mainly acts by modifying the cortical excitability, which majorly depends on the stimulation frequency. It was shown that low frequencies $(<1 \mathrm{~Hz})$ and high frequencies $(>5 \mathrm{~Hz})$ have respectively inhibitory and excitatory effects (Pascual-Leone et al., 1994). Over the last few years, rTMS has gained special interest in the management of MS symptoms. For instance, rTMS over the motor cortex was shown to provide beneficial effects on spasticity (Centonze et al., 2007a), lower urinary tract (LUT) symptoms (Centonze et al., 2007b), and hand dexterity (Koch et al., 2008) in MS patients. Furthermore, intermittent theta burst stimulation (iTBS) -a variant of TMS- ameliorated MS spasticity (Mori et al., 2010a,b) and primed the exercise effect in MS patients (Mori et al., 2011).

As for tDCS, the idea of using electrical current stimulation to modulate brain function dates back to more than 200 years (Priori, 2003; Zago et al., 2008). Data from animal studies revealed that weak direct currents delivered by intracerebral or epidural electrodes were able to modify cortical excitability, an effect that remains stable long after the end of stimulation. In the last few decades, tDCS showed its reliability in changing human cortical function by inducing focal, prolonged yet reversible shifts in cortical excitability (Priori et al., 1998; Nitsche and Paulus, 2000, 2001; Nitsche et al., 2003; Priori, 2003). The technique consists of localizing two electrodes over the scalp, an anode and a cathode, in order to act on various neural circuits. The exposed tissue is polarized and tDCS modifies spontaneous neuronal excitability by a tonic depolarization or hyperpolarization of resting membrane potential, obtained respectively by performing anodal or cathodal tDCS (Creutzfeldt et al., 1962; Purpura and McMurtry, 1965; Nitsche and Paulus, 2011; Paulus et al., 2013; Filmer et al., 2014). tDCS effects depend on several parameters including the electrodes size, type, polarity, and position as well as the current strength and shape, and the stimulation duration (Purpura and McMurtry, 1965; Nitsche and Fregni, 2007; Nitsche et al., 2008).

Moreover, tDCS appears to be an NIBS technique with a good safety profile, easy implementation, good patients' tolerance and little or no adverse effects (Poreisz et al., 2007; Nitsche et al., 2008; Brunoni et al., 2012). In addition, compared to 
rTMS, placebo-controlled studies are easier to be performed with tDCS since real and sham stimulations are quite indistinguishable (Gandiga et al., 2006). For all these reasons, tDCS would be an important therapeutic modality for cortical dysfunction (Been et al., 2007) constituting an interesting option in the management of MS symptoms, notably fatigue.

Before reviewing NIBS data in terms of MS fatigue, we will present the various aspects that support the specific interest of tDCS use to treat MS-related brain dysfunction.

\section{Specific Interests of tDCS in the Management of MS-related Disorders tDCS and Brain Functional Connectivity}

The modulatory effects of tDCS in terms of the rs-FC of various networks have been supported by numerous fMRI and MRS studies. For instance, anodal tDCS over the left DLPFC increased its connectivity with the right hemisphere (Park et al., 2013) and modified the rs-FC in the fronto-parietal networks (Keeser et al., 2011). In addition, the tDCS effects on brain networks connectivity were demonstrated following motor cortex, left and right inferior frontal gyri (IFG) stimulation. Anodal stimulation of the former would lead to FC changes some of which occur within the cortico-striatal and thalamo-cortical circuits (Polanía et al., 2011a,b, 2012a,b; Sehm et al., 2012, 2013; Amadi et al., 2013; Khan et al., 2013; Lindenberg et al., 2013). Furthermore, acting on the left or right IFG had an important impact on the rs-FC of the language network (Meinzer et al., 2012, 2013; Rosso et al., 2014).

Therefore, based on these data, tDCS might be beneficial in modulating MS-fatigue networks and restoring brain FC through several potential mechanisms.

\section{tDCS, Conduction Failure, and Axonal Degeneration}

Major changes in axonal conduction occur in MS as a result of the inflammatory demyelinating processes and the oxidative stress. First, among the inflammatory mediators, nitric oxide can cause a depolarizing conduction block (Redford et al., 1997; Shrager et al., 1998) which may occur through the activation of persistent $\mathrm{Na}^{+}$channels and the subsequent increase in intracellular $\mathrm{Na}^{+}$; or by causing a mitochondrial dysfunction and axonal ATP depletion (Bolanos et al., 1997). The latter can explain the documented $\mathrm{Na}^{+} / \mathrm{K}^{+}$ATPase failure (Dutta et al., 2006; Waxman, 2006; Mahad et al., 2008) and the reverse action of $\mathrm{Na}^{+}-\mathrm{Ca}^{2+}$ exchanger, leading to intraaxonal calcium level increase, activation of $\mathrm{Ca}^{2+}$-dependent apoptosis and axonal degeneration (Bechtold and Smith, 2005; Stys, 2005; Gonsette, 2008). Interestingly, one study has shown that tDCS might act on these mechanisms by modulating the activity of $\mathrm{Na}^{+}$and $\mathrm{Ca}^{2+}$ channels (Nitsche et al., 2003). Furthermore, in the rat model of Parkinson disease, tDCS was able to reduce the oxidative stress, which resulted in a cognitive improvement ( $\mathrm{Lu}$ et al., 2015). Hence, anodal tDCS might enhance axonal conduction along the demyelinated segments through a subthreshold polarizing effect. This might be used to improve MS fatigue.

Beyond demyelination, MS can lead to axonal degeneration, associated with irreversible deficits. Notably, two recent animal studies have documented a positive effect of tDCS on the activation and migration of neural stem cells (Rueger et al.,
2012; Keuters et al., 2015). Therefore, tDCS could be helpful in promoting the regeneration processes and ameliorating various MS symptoms in the course of the disease.

\section{tDCS and Inflammation-induced Synaptopathy}

Inflammation-induced synaptopathy is the link between inflammation and neurodegeneration, as shown in the animal model of MS. Inflammation might limit the plastic compensatory protective changes in neural networks, which can be the route by which CNS confined inflammation shifts into irreversible neurodegenerative disorders (Centonze et al., 2010). Glutamate is a major excitatory neurotransmitter of the CNS, importantly involved in MS neurodegenerative damage (Srinivasan et al., 2005; Cianfoni et al., 2007). Altered glutamate metabolism and the subsequent abnormal intracellular ion accumulation can lead to excitotoxic neuronal damage (Forder and Tymianski, 2009). MS patients were found to have increased CSF levels of glutamate (Stover et al., 1997; Sarchielli et al., 2003; Srinivasan et al., 2005; Cianfoni et al., 2007), upregulation of glutamate receptors (Newcombe et al., 2008), and altered expression of glutamate transporters (Geurts et al., 2003, 2005; Vallejo-Illarramendi et al., 2006).

In addition, inflammation-dependent activation of the microglia is associated with the release of TNF- $\alpha$, IFN- $\gamma$, and IL$1 \beta$ (Block and Hong, 2005; Kawanokuchi et al., 2006; Schwartz et al., 2006; Muzio et al., 2007), which can enhance the excitatory synaptic transmission (Stellwagen et al., 2005; Lai et al., 2006; Mizuno et al., 2008), and downregulate the inhibitory Gamma Amino-Butyric acid (GABA) transmission (Stellwagen et al., 2005). These facts are compatible with the case of MS patients who are known to have increased CSF levels of TNF- $\alpha$, IFN- $\gamma$, and IL-1 $\beta$, among other inflammatory mediators (Rovaris et al., 1996; Khademi et al., 2000; Baraczka et al., 2003).

These findings altogether may explain the inflammationinduced synaptic alterations and the subsequent neurodegenerative processes in MS, and might in turn account for the appearance of MS fatigue.

Knowing the interaction between tDCS and long-term changes in neurotransmission, tDCS effects might occur through the modulation of inflammation-induced synaptopathy in MS patients. For instance, two pharmacological studies have found that tDCS-induced after-effects take place via the modulation of NDMA glutamatergic receptor activity, which are known to be highly implicated in neuroplasticity (Liebetanz et al., 2002; Nitsche et al., 2003). Furthermore, anodal and cathodal tDCS were found to respectively decrease GABA and glutamate levels (Stagg et al., 2009). Interestingly, anodal tDCS was found to significantly increase the combined glutamate and glutamine levels beneath the stimulating electrode (Clark et al., 2011; Hunter et al., 2015). Finally, in one study combining MRS and $\mathrm{AMRI}$ assessment, anodal tDCS over the motor cortex was found to increase motor learning by increasing the resting motor network FC, probably through a decrease in motor cortex GABA levels (Stagg et al., 2014).

Along with the GABA and glutamate changes encountered in MS, a recent work has introduced the dopamine hypothesis in MS fatigue (Dobryakova et al., 2015). Dopamine neurotransmission 
is also likely involved in NIBS-induced cortical neuroplasticity (Fresnoza et al., 2004, 2014; Nitsche et al., 2006, 2009, 2010; Kuo et al., 2008; Monte-Silva et al., 2009, 2010, 2011; Tanaka et al., 2013).

Thus, tDCS could promote various beneficial synaptic changes which might be helpful in counteracting the deleterious impact of MS on neurotransmission and possibly alleviating fatigue.

\section{NIBS Studies in MS Fatigue}

To the best of our knowledge, the effects of NIBS on MS fatigue have been evaluated in four studies so far, three of which were based on tDCS use in a double-blind, sham-controlled, crossover design (Ferrucci et al., 2014; Saiote et al., 2014; Tecchio et al., 2014) (Table 6). These studies consisted of two blocks of five consecutive daily sessions of either real or sham tDCS.

In the first study, Ferruci et al. applied daily sessions of sham or active anodal tDCS over M1 bilaterally, blocks were held apart by at least 1 month (Ferrucci et al., 2014). Two-third of the patients were found to have a significant improvement in their fatigue scores, up to the third week following active tDCS. Sham condition did not result in any significant effects. Interestingly, "responder" patients were found to be younger than their "non-responder" counterparts; no other significant difference was found between both groups in terms of disease duration and severity. Such a difference is quite interesting and could partly explain the results since older patients might be less susceptible to the neuroplasticity processes which could render them less responsive to tDCS (Boggio et al., 2010).

A second study assessed the effects of anodal tDCS over the left DLPFC (Saiote et al., 2014). Fatigue scores improved in about half of the patients following both active and sham tDCS, without any significant difference between the two conditions. The lack of difference between both stimulation conditions could have been resulted from a carry-over effect since stimulation blocks were separated by only 2 weeks which might be too short to exclude interference.

In the third study, following navigation-guided anodal tDCS over the bilateral somatosensory cortices, all patients significantly improved after real but not sham stimulations (Tecchio et al., 2014). Clinical improvement ranged from 2 to 76\% and lasted for 8 weeks. Such results can be accounted by some facts. First, concerning stimulation target, the bilateral somatosensory areas are quite and involve the representation areas of the face, upper limbs and lower limbs bilaterally; which might explain its greater efficacy compared to the stimulation of the bilateral hand motor areas or the left DLPFC selected in the abovementioned studies. Second, regarding the study design, the authors stated that the stimulation blocks were not performed in summertime to avoid the induction of fatigue by hot temperatures. In addition, unlike the washout intervals adapted in the other two studies ( 2 weeks vs. 4 weeks, respectively), a strict washout interval was defined by the authors. In other terms, a patient who completed the first stimulation block was not allowed to have the second one until the MFIS score at the follow-up evaluation satisfies the following condition: $\frac{\text { MFIS at evaluation -MFIS preblock1 }}{\text { MFIS preblock1 }}<0.5 \times \frac{\text { MFIS postblock1-MFIS preblock1 }}{\text { MFIS preblock1 }}$.

This might have minimized any possible carry-over effects that usually add difficulties to the results interpretation. Furthermore, the combination of neuronavigation technique with tDCS could have optimized the outcomes, keeping in mind the superior role of neuronavigation compared to the classical non-navigated interventions (Lefaucheur, 2010).

Apart from tDCS, one iTBS protocol was performed to determine its effects on spasticity, fatigue, and quality of life in 30 RRMS patients: iTBS was applied with or without

TABLE 6 | Studies investing the effects of transcranial direct current stimulation (tDCS) on multiple sclerosis fatigue.

Ferrucci et al., 2014

Randomized, double-blinded, sham-controlled, crossover study (washout interval: 1 month)

Design
Saiote et al., 2014

Pseudo-randomized, double-blind, sham-controlled, counterbalanced, crossover study (washout interval: 2 weeks)

Left DLPFC
25 RRMS
Fatigue for at least 2 month defined as FSS $\geq$
4; EDSS $\leq 6$
MFIS, FSS, MS specific FSS
Anode at F3 (10-20 EEG system); cathode
placed on the contralateral forehead
$1 \mathrm{~mA}$, for 20 min
No significant changes in fatigue scores
following stimulation. Changes in perceived
fatigue lasting up to day 30 . Correlation
between lesion load and response to tDCS

Tecchio et al., 2014

Randomized, double-blinded, sham-controlled, counterbalanced crossover study (washout "completed" when the percentage of MFIS difference from baseline becomes $<0.5$ of induced effect)

Bilateral whole body $\mathrm{S} 1$

7 RRMS, 2 PP, 1 SP

Experiencing fatigue defined as MFIS > 38; EDSS $\leq 3.5$

MFIS

Anode on the central sulcus trace; the reference electrode at $\mathrm{Oz}$ (10-20 EEG system). $1.5 \mathrm{~mA}$, for $15 \mathrm{~min}$

Long term sustainable effects up to at least 2 months

Results

Long-term sustainable effect up to the 3rd week. No correlation between fatigue response and age, disease duration, and EDSS

DLPFC, dorsolateral prefrontal cortex; FIS, Fatigue impact scale, FSS, Fatigue Severity Scale; MFIS, Modified Fatigue Impact Scale; M1, primary motor cortex; PP, primary progressive; RRMS, relapsing remitting multiple sclerosis; SP, secondary progressive; S1, primary somatosensory cortex; EDSS, Expanded Disability Status Scale. 
exercise therapy in a sham-controlled manner (Mori et al., 2011). The stimulation coil was positioned over the M1 leg region contralaterally to the most affected limb, for 10 sessions (protocol duration: 2 weeks; 10 bursts; 600 pulses). iTBS combined with exercise therapy was significantly able to reduce spasticity and fatigue, ameliorating the quality of life. However, iTBS alone could only decrease spasticity, without having any effect on fatigue. Although interesting, such preliminary results need to be replicated and further assessed in future works.

\section{CONCLUSION}

These data altogether suggest that during the course of the disease, the inflammation along with the demyelination, synaptopathy and neurodegeneration might lead to several structural and functional abnormalities in cortico-subcortical circuits. The latter can take parts in the cortico-striato-thalamocortical loop of MS fatigue. Considering MS as a spectrum where the extreme destructive sequels of an MS-attack lie on one pole, and the potential healing and neuroplasticity processes on the other; the clinical manifestations do not seem

\section{REFERENCES}

Amadi, U., Ilie, A., Johansen-Berg, H., and Stagg, C. J. (2013). Polarity-specific effects of motor transcranial direct current stimulation on fMRI resting state networks. Neuroimage 88C, 155-161. doi: 10.1016/j.neuroimage.2013.11.037

Andreasen, A. K., Jakobsen, J., Soerensen, L., Andersen, H., Petersen, T., Bjarkam, C. R., et al. (2010). Regional brain atrophy in primary fatigued patients with multiple sclerosis. Neuroimage 50, 608-615. doi: 10.1016/j.neuroimage.2009.12.118

Bakshi, R. (2003). Fatigue associated with multiple sclerosis: diagnosis, impact and management. Mult. Scler. 9, 219-227. doi: 10.1191/1352458503ms 904 oa

Bakshi, R., Miletich, R. S., Henschel, K., Shaikh, Z. A., Janardhan, V., Wasay, M., et al. (1999). Fatigue in multiple sclerosis: cross-sectional correlation with brain MRI findings in 71 patients. Neurology 53, 1151-1153. doi: 10.1212/WNL.53.5.1151

Bakshi, R., Shaikh, Z. A., Miletich, R. S., Czarnecki, D., Dmochowski, J., Henschel, K., et al. (2000). Fatigue in multiple sclerosis and its relationship to depression and neurologic disability. Mult. Scler. 6, 181-185. doi: $10.1177 / 135245850000600308$

Baraczka, K., Pozsonyi, T., Szüts, I., Ormos, G., and Nékám, K. (2003). Increased levels of tumor necrosis alpha and soluble vascular endothelial adhesion molecule- 1 in the cerebrospinal fluid of patients with connective tissue diseases and multiple sclerosis. Acta Microbiol. Immunol. Hung. 50, 339-348. doi: 10.1556/AMicr.50.2003.4.3

Bechtold, D. A., and Smith, K. J. (2005). Sodium-mediated axonal degeneration in inflammatory demyelinating disease. J. Neurol. Sci. 233, 27-35. doi: 10.1016/j.jns.2005.03.003

Been, G., Ngo, T. T., Miller, S. M., and Fitzgerald, P. B. (2007). The use of tDCS and CVS as methods of noninvasive brain stimulation. Brain Res. Rev. 56, 346-361. doi: 10.1016/j.brainresrev.2007.08.001

Benedict, R. H., Wahlig, E., Bakshi, R., Fishman, I., Munschauer, F., and Zivadinov, R. (2005). Predicting quality of life in multiple sclerosis: accounting for physical disability, fatigue, cognition, mood disorder, personality, and behavior change. J. Neurol. Sci. 231, 29-34. doi: 10.1016/j.jns.2004.12.009

Bertolone, K., Coyle, P. K., Krupp, L. B., and Doscher, C. A. (1993). Cytokine correlates of fatigue in multiple sclerosis. Neurology 43, A356.

Bester, M., Lazar, M., Petracca, M., Babb, J. S., Herbert, J., Grossman, R. I., et al. (2013). Tract-specific white matter correlates of fatigue and cognitive to exclusively depend on the structural damage, but rather on the balance between restorative and inflammatory/degenerative processes. This vision can be applied to the fatigue loop, the breakdown of which might result in the co-occurrence of the physical, mental, and psychosocial domains of fatigue. Facing the pharmacological limitations in treating MS fatigue, NIBS would pave the way for better therapeutics, especially that tDCS has a promising role in modulating the fatigue loop. In this perspective, optimizing the future protocols would be by acting on several factors. For instance, knowing that tDCS effects on MS fatigue can last for several weeks, extending the washout intervals might clarify the effects of each stimulation blocks by prohibiting the possibility of interference. Furthermore, in the light of discrepancy between the frequently administered fatigue scores and the change in the perceived fatigue on one side, and the complexity of this symptom on the other side, future studies might benefit from adapting better assessment tools, such as the visual analog scale for fatigue. Lastly, combining tDCS protocols with functional imaging would allow for a better understanding of the fatigue loop, which would further help in designing and tuning the ultimate therapeutic plans in MS fatigue.

impairment in benign multiple sclerosis. J. Neurol. Sci. 330, 61-66. doi: 10.1016/j.jns.2013.04.005

Block, M. L., and Hong, J. S. (2005). Microglia and inflammation-mediated neurodegeneration: multiple triggers with a common mechanism. Prog. Neurobiol. 76, 77-98. doi: 10.1016/j.pneurobio.2005.06.004

Boggio, P. S., Campanhã, C., Valasek, C. A., Fecteau, S., Pascual-Leone, A., and Fregni, F. (2010). Modulation of decision-making in a gambling task in older adults with transcranial direct current stimulation. Eur. J. Neurosci. 31, 593-597. doi: 10.1111/j.1460-9568.2010.07080.x

Bol, Y., Smolders, J., Duits, A., Lange, I. M., Romberg-Camps, M., and Hupperts, R. (2012). Fatigue and heat sensitivity in patients with multiple sclerosis. Acta Neurol. Scand. 126, 384-389. doi: 10.1111/j.1600-0404.2012.01660.x

Bolaños, J. P., Almeida, A., Stewart, V., Peuchen, S., Land, J. M., Clark, J. B., et al. (1997). Nitric oxide mediated mitochondrial damage in the brain: mechanisms and implications for neurodegenerative diseases. J. Neurochem. 68, 2227-2240. doi: 10.1046/j.1471-4159.1997.68062227.x

Braley, T. J., and Chervin, R. D. (2010). Fatigue in multiple sclerosis: mechanisms, evaluation, and treatment. Sleep 33, 1061-1067.

Brunoni, A. R., Nitsche, M. A., Bolognini, N., Bikson, M., Wagner, T., Merabet, L., et al. (2012). Clinical research with transcranial direct current stimulation (tDCS): challenges and future directions. Brain Stimul. 5, 175-195. doi: 10.1016/j.brs.2011.03.002

Calabrese, M., Rinaldi, F., Grossi, P., Mattisi, I., Bernardi, V., Favaretto, A., et al. (2010). Basal ganglia and frontal/parietal cortical atrophy is associated with fatigue in relapsing-remitting multiple sclerosis. Mult. Scler. 16, 1220-1228. doi: $10.1177 / 1352458510376405$

Centonze, D., Koch, G., Versace, V., Mori, F., Rossi, S., Brusa, L., et al. (2007a). Repetitive transcranial magnetic stimulation of the motor cortex ameliorates spasticity in multiple sclerosis. Neurology 68, 1045-1050. doi: 10.1212/01.wnl.0000257818.16952.62

Centonze, D., Muzio, L., Ross, S., Furlan, R., Bernardi, G., and Martino, G. (2010). The link between inflammation, synaptic transmission and neurodegeneration in multiple sclerosis. Cell Death Differ. 17, 1083-1091. doi: 10.1038/cdd.2009.179

Centonze, D., Petta, F., Versace, V., Rossi, S., Torelli, F., Prosperetti, C., et al. (2007b). Effects of motor cortex rTMS on lower urinary tract dysfunction in multiple sclerosis. Mult. Scler. 13, 269-271. doi: 10.1177/1352458506070729

Chaudhuri, A., and Behan, P. O. (2000). Fatigue and basal ganglia. J. Neurol. Sci. 179, 34-42. doi: 10.1016/S0022-510X(00)00411-1 
Cianfoni, A., Niku, S., and Imbesi, S. G. (2007). Metabolite findings in tumefactive demyelinating lesions utilizing short echo time proton magnetic resonance spectroscopy. AJNR Am. J. Neuroradiol. 28, 272-277.

Clark, V. P., Coffman, B. A., Trumbo, M. C., and Gasparovic, C. (2011). Transcranial direct current stimulation (tDCS) produces localized and specific alterations in neurochemistry: a ${ }^{1} \mathrm{H}$ magnetic resonance spectroscopy study. Neurosci. Lett. 500, 67-71. doi: 10.1016/j.neulet.2011.05.244

Claros-Salinas, D., Dittmer, N., Neumann, M., Sehle, A., Spiteri, S., Willmes, K., et al. (2013). Induction of cognitive fatigue in MS patients through cognitive and physical load. Neuropsychol. Rehabil. 23, 182-201. doi: 10.1080/09602011.2012.726925

Codella, M., Rocca, M. A., Colombo, B., Martinelli-Boneschi, F., Comi, G., and Filippi, M. (2002b). Cerebral grey matter pathology and fatigue in patients with multiple sclerosis: a preliminary study. J. Neurol. Sci. 194, 71-74. doi: 10.1016/S0022-510X(01)00682-7

Codella, M., Rocca, M. A., Colombo, B., Rossi, P., Comi, G., and Filippi, M. (2002a). A preliminary study of magnetization transfer and diffusion tensor MRI of multiple sclerosis patients with fatigue. J. Neurol. 249, 535-537. doi: $10.1007 / \mathrm{s} 004150200060$

Colombo, B., Martinelli Boneschi, F., Rossi, P., Rovaris, M., Maderna, L., Filippi, M., et al. (2000). MRI and motor evoked potential findings in nondisabled multiple sclerosis patients with and without symptoms of fatigue. J. Neurol. 247, 506-509. doi: 10.1007/s004150070148

Colosimo, C., Millefiorini, E., Grasso, M. G., Vinci, F., Fiorelli, M., Koudriavtseva, T., et al. (1995). Fatigue in multiple sclerosis is associated with specific clinical features. Acta Neurol. Scand. 92, 353-355. doi: 10.1111/j.16000404.1995.tb00145.x

Comi, G., Leocani, L., Rossi, P., and Colombo, B. (2001). Physiopathology and treatment of fatigue in multiple sclerosis. J. Neurol. 248, 174-179. doi: $10.1007 / \mathrm{s} 004150170222$

Compston, A., and Coles, A. (2008). Multiple sclerosis. Lancet 372, 1502-1517. doi: 10.1016/S0140-6736(08)61620-7

Creutzfeldt, O. D., Fromm, G. H., and Kapp, H. (1962). Influence of transcortical D-C currents on cortical neuronal activity. Exp. Neurol. 5, 436-452. doi: 10.1016/0014-4886(62)90056-0

Cruz Gómez, Á. J., Ventura Campos, N., Belenguer, A., Ávila, C., and Forn, C. (2013). Regional brain atrophy and functional connectivity changes related to fatigue in multiple sclerosis. PLOS ONE 8:e77914. doi: 10.1371/journal.pone.0077914

DeLuca, J., Genova, H. M., Hillary, F. G., and Wylie, G. (2008). Neural correlates of cognitive fatigue in multiple sclerosis using functional MRI. J. Neurol. Sci. 270, 28-39. doi: 10.1016/j.jns.2008.01.018

Derache, N., Grassiot, B., Mézenge, F., Emmanuelle Dugué, A., Desgranges, B., Constans, J. M., et al. (2013). Fatigue is associated with metabolic and density alterations of cortical and deep gray matter in relapsing-remitting-multiple sclerosis patients at the earlier stage of the disease: A PET/MR study. Mult. Scler. Relat. Disord. 2, 362-369. doi: 10.1016/j.msard.2013.03.005

Dobryakova, E., Genova, H. M., DeLuca, J., and Wylie, G. R. (2015). The dopamine imbalance hypothesis of fatigue in multiple sclerosis and other neurological disorders. Front. Neurol. 6:52. doi: 10.3389/fneur.2015.00052

Dutta, R., McDonough, J., Yin, X., Peterson, J., Chang, A., Torres, T., et al. (2006). Mitochondrial dysfunction as a cause of axonal degeneration in multiple sclerosis patients. Ann. Neurol. 59, 478-489. doi: 10.1002/ana.20736

Engström, M., Flensner, G., Landtblom, A. M., Ek, A. C., and Karlsson, T. (2013). Thalamo-striato-cortical determinants to fatigue in multiple sclerosis. Brain Behav. 3, 715-728. doi: 10.1002/brb3.181

Ferrucci, R., Vergari, M., Cogiamanian, F., Bocci, T., Ciocca, M., Tomasini, E., et al. (2014). Transcranial direct current stimulation (tDCS) for fatigue in multiple sclerosis. NeuroRehabilitation 34, 121-127. doi: 10.3233/NRE-131019

Filippi, M., Rocca, M. A., Colombo, B., Falini, A., Codella, M., Scotti, G., et al. (2002). Functional magnetic resonance imaging correlates of fatigue in multiple sclerosis. Neuroimage 15, 559-567. doi: 10.1006/nimg.2001.1011

Filmer, H. L., Dux, P. E., and Mattingley, J. B. (2014). Applications of transcranial direct current stimulation for understanding brain function. Trends Neurosci. 37, 742-753. doi: 10.1016/j.tins.2014.08.003

Finke, C., Schlichting, J., Papazoglou, S., Scheel, M., Freing, A., Soemmer, C., et al. (2014). Altered basal ganglia functional connectivity in multiple sclerosis patients with fatigue. Mult. Scler. 21, 925-934. doi: 10.1177/1352458514555784
Fisk, J. D., Pontefract, A., Ritvo, P. G., Archibald, C. J., and Murray, T. J. (1994b). The impact of fatigue on patients with multiple sclerosis. Can. J. Neurol. Sci. 21, 9-14.

Fisk, J. D., Ritvo, P. G., Ross, L., Haase, D. A., Marrie, T. J., and Schlech, W. F. (1994a). Measuring the functional impact of fatigue: initial validation of the fatigue impact scale. Clin. Infect. Dis. 18, S79-S83. doi: 10.1093/clinids/18.Supplement_1.S79

Flachenecker, P., Bihler, I., Weber, F., Gottschalk, M., Toyka, K. V., and Rieckmann, P. (2004). Cytokine mRNA expression in patients with multiple sclerosis and fatigue. Mult. Scler. 10, 165-169. doi: 10.1191/1352458504ms9910a

Flachenecker, P., Kümpfel, T., Kallmann, B., Gottschalk, M., Grauer, O., and Rieckmann, P. (2002). Fatigue in multiple sclerosis: a comparison of different rating scales and correlation to clinical parameters. Mult. Scler. 8, 523-526. doi: $10.1191 / 1352458502 \mathrm{~ms} 839$ oa

Flensner, G., Ek, A. C., Landtblom, A. M., and Söderhamn, O. (2008). Fatigue in relation to perceived health: people with multiple sclerosis compared with people in the general population. Scand. J. Caring Sci. 22, 391-400. doi: 10.1111/j.1471-6712.2007.00542.x

Ford, H., Trigwell, P., and Johnson, M. (1998). The nature of fatigue in multiple sclerosis. J. Psychosom. Res. 45, 33-38. doi: 10.1016/S0022-3999(98)00004-X

Forder, J. P., and Tymianski, M. (2009). Postsynaptic mechanisms of excitotoxicity: involvement of postsynaptic density proteins, radicals, and oxidant molecules. Neuroscience 158, 293-300. doi: 10.1016/j.neuroscience.2008.10.021

Fresnoza, S., Paulus, W., Nitsche, M. A., and Kuo, M. F. (2014). Nonlinear dosedependent impact of D1 receptor activation on motor cortex plasticity in humans. J. Neurosci. 34, 2744-2753. doi: 10.1523/JNEUROSCI.3655-13.2014

Fresnoza, S., Stiksrud, E., Klinker, F., Liebetanz, D., Paulus, W., Kuo, M. F., et al. (2004). Dosage-dependent effect of dopamine D2 receptor activation on motor cortex plasticity in humans. J. Neurosci. 34, 10701-10709. doi: 10.1523/JNEUROSCI.0832-14.2014

Gandevia, S. C. (2001). Spinal and supraspinal factors in human muscle fatigue. Physiol. Rev. 81, 1725-1789.

Gandiga, P. C., Hummel, F. C., and Cohen, L. G. (2006). Transcranial DC stimulation (tDCS): A tool for double-blind sham-controlled clinical studies in brain stimulation. Clin. Neurophysiol. 117, 845-850. doi: 10.1016/j.clinph.2005.12.003

Genova, H. M., Rajagopalan, V., Deluca, J., Das, A., Binder, A., and Arjunan, A. (2013). Examination of cognitive fatigue in multiple sclerosis using functional magnetic resonance imaging and diffusion tensor imaging. PLoS ONE 8:e78811. doi: 10.1371/journal.pone.0078811

Geurts, J. J., Wolswijk, G., Bö, L., Redeker, S., Ramkema, M., Troost, D., et al. (2005). Expression patterns of Group III metabotropic glutamate receptors mGluR4 and mGluR8 in multiple sclerosis lesions. J. Neuroimmunol. 158, 182-190. doi: 10.1016/j.jneuroim.2004.08.012

Geurts, J. J., Wolswijk, G., Bö, L., van der Valk, P., Polman, C. H., Troost, D., et al. (2003). Altered expression patterns of group I and II metabotropic glutamate receptors in multiple sclerosis. Brain 126, 1755-1766. doi: $10.1093 /$ brain/awg179

Giovannoni, G. (2006). Multiple sclerosis related fatigue. J. Neurol. Neurosurg. Psychiatry 77, 2-3. doi: 10.1136/jnnp.2005.074948

Gobbi, C., Rocca, M. A., Pagani, E., Riccitelli, G. C., Pravatà, E., Radaelli, M., et al. (2014b). Forceps minor damage and co-occurrence of depression and fatigue in multiple sclerosis. Mult. Scler. 20, 1633-1640. doi: 10.1177/135245851 4530022

Gobbi, C., Rocca, M. A., Riccitelli, G., Pagani, E., Messina, R., Preziosa, P., et al. (2014a). Influence of the topography of brain damage on depression and fatigue in patients with multiple sclerosis. Mult. Scler. 20, 192-201. doi: $10.1177 / 1352458513493684$

Gold, S. M., Krüger, S., Ziegler, K. J., Krieger, T., Schulz, K. H., Otte, C., et al. (2011). Endocrine and immune substrates of depressive symptoms and fatigue in multiple sclerosis patients with comorbid major depression. J. Neurol. Neurosurg. Psychiatry 82, 814-818. doi: 10.1136/jnnp.2010.230029

Gonsette, R. E. (2008). Neurodegeneration in multiple sclerosis: the role of oxidative stress and excitotoxicity. J. Neurol. Sci. 274, 48-53. doi: 10.1016/j.jns.2008.06.029

Gottschalk, M., Kümpfel, T., Flachenecker, P., Uhr, M., Trenkwalder, C., Holsboer, F., et al. (2005). Fatigue and regulation of the 
hypothalamo-pituitary-adrenal axis in multiple sclerosis. Arch. Neurol. 62, 277-280. doi: 10.1001/archneur.62.2.277

Hanken, K., Eling, P., Kastrup, A., Klein, J., and Hildebrandt, H. (2015). Integrity of hypothalamic fibers and cognitive fatigue in multiple sclerosis. Mult. Scler. Relat. Disord. 4, 39-46. doi: 10.1016/j.msard.2014.11.006

Heesen, C., Nawrath, L., Reich, C., Bauer, N., Schulz, K.-H., and Gold, S. M. (2006). Fatigue in multiple sclerosis: an example of cytokine mediated sickness behaviour? J. Neurol. Neurosurg. Psychiatry 77, 34-39. doi: 10.1136/jnnp.2005.065805

Hesse, S., Moeller, F., Petroff, D., Lobsien, D., Luthardt, J., Regenthal, R., et al. (2014). Altered serotonin transporter availability in patients with multiple sclerosis. Eur. J. Nucl. Med. Mol. Imaging 41, 1640-1641. doi: 10.1007/s00259014-2790-y

Hoepner, R., Faissner, S., Salmen, A., Gold, R., and Chan, A. (2014). Efficacy and side effects of natalizumab therapy in patients with multiple sclerosis. J. Cent. Nerv. Syst. Dis. 6, 41-49. doi: 10.4137/JCNSD.S14049

Hunter, M. A., Coffman, B. A., Gasparovic, C., Calhoun, V. D., Trumbo, M. C., and Clark, V. P. (2015). Baseline effects of transcranial direct current stimulation on glutamatergic neurotransmission and large-scale network connectivity. Brain Res. 1594, 92-107. doi: 10.1016/j.brainres.2014.09.066

Huolman, S., Hämäläinen, P., Vorobyev, V., Ruutiainen, J., Parkkola, R., Laine, T., et al. (2011). The effects of rivastigmine on processing speed and brain activation in patients with multiple sclerosis and subjective cognitive fatigue. Mult. Scler. 17, 1351-1361. doi: 10.1177/1352458511412061

Induruwa, I., Constantinescu, C. S., and Gran, B. (2012). Fatigue in multiple sclerosis - a brief review. J. Neurol. Sci. 323, 9-15. doi: 10.1016/j.jns.2012.08.007

Inglese, M., Park, S. J., Johnson, G., Babb, J. S., Miles, L., Jaggi, H., et al. (2007). Deep gray matter perfusion in multiple sclerosis: dynamic susceptibility contrast perfusion magnetic resonance imaging at 3 T. Arch. Neurol. 64, 196-202. doi: 10.1001/archneur.64.2.196

Janardhan, V., and Bakshi, R. (2002). Quality of life in patients with multiple sclerosis: the impact of fatigue and depression. J. Neurol. Sci. 205, 51-58. doi: 10.1016/S0022-510X(02)00312-X

Kawanokuchi, J., Mizuno, T., Takeuchi, H., Kato, H., Wang, J., Mitsuma, N., et al. (2006). Production of interferon-gamma by microglia. Mult. Scler. 12, 558-564. doi: $10.1177 / 1352458506070763$

Keeser, D., Meindl, T., Bor, J., Palm, U., Pogarell, O., Mulert, C., et al. (2011). Prefrontal transcranial direct current stimulation changes connectivity of resting-state networks during fMRI. J. Neurosci. 31, 15284-15293. doi: 10.1523/JNEUROSCI.0542-11.2011

Keuters, M. H., Aswendt, M., Tennstaedt, A., Wiedermann, D., Pikhovych, A., Rotthues, S., et al. (2015). Transcranial direct current stimulation promotes the mobility of engrafted NSCs in the rat brain. NMR Biomed. 28, 231-239. doi: $10.1002 / \mathrm{nbm} .3244$

Khademi, M., Wallström, E., Andersson, M., Piehl, F., Di Marco, R., and Olsson, T. (2000). Reduction of both pro- and anti-inflammatory cytokines after 6 months of interferon beta-1a treatment of multiple sclerosis. J. Neuroimmunol. 103, 202-210. doi: 10.1016/S0165-5728(99)00184-8

Khan, B., Hodics, T., Hervey, N., Kondraske, G., Stowe, A. M., and Alexandrakis, G. (2013). Functional near-infrared spectroscopy maps cortical plasticity underlying altered motor performance induced by transcranial direct current stimulation. J. Biomed. Opt. 18:116003. doi: 10.1117/1.JBO.18. 11.116003

Khan, F., Amatya, B., and Galea, M. (2014). Management of fatigue in persons with multiple sclerosis. Front. Neurol. 5:177. doi: 10.3389/fneur.2014.00177

Kluger, B. M., Krupp, L. B., and Enoka, R. M. (2013). Fatigue and fatigability in neurologic illnesses: proposal for a unified taxonomy. Neurology 80, 409-416. doi: 10.1212/WNL.0b013e31827f07be

Koch, G., Rossi, S., Prosperetti, C., Codecà, C., Monteleone, F., Petrosini, L., et al. (2008). Improvement of hand dexterity following motor cortex rTMS in multiple sclerosis patients with cerebellar impairment. Mult. Scler. 14, 995-998. doi: $10.1177 / 1352458508088710$

Kos, D., Kerckhofs, E., Nagels, G., D’hooghe, M. B., and Ilsbroukx, S. (2008). Origin of fatigue in multiple sclerosis: review of the literature. Neurorehabil. Neural Repair 22, 91-100. doi: 10.1177/1545968306298934

Krupp, L. B. (2003). The Most Common Complaints: Fatigue. Philadelphia, PA: Butterworth Heinemann-Elsevier Science.
Krupp, L. B., Alvarez, L. A., LaRocca, N. G., and Scheinberg, L. C. (1988). Fatigue in multiple sclerosis. Arch. Neurol. 45, 435-437. doi: 10.1001/ archneur.1988.00520280085020

Krupp, L. B., LaRocca, N. G., Muir-Nash, J., and Steinberg, A. D. (1989). The fatigue severity scale. Arch. Neurol. 46, 1121-1123. doi: 10.1001/archneur. 1989.00520460115022

Krupp, L. B., Serafin, D. J., and Christodoulou, C. (2010). Multiple sclerosis associated fatigue. Expert. Rev. Neurother. 10, 1437-1447. doi: 10.1586/ ern.10.99

Kuo, M. F., Paulus, W., and Nitsche, M. A. (2008). Boosting focally-induced brain plasticity by dopamine. Cereb. Cortex 18, 648-651. doi: 10.1093/cercor/bhm098

Lai, A. Y., Swayze, R. D., El-Husseini, A., and Song, C. (2006). Interleukin-1 beta modulates AMPA receptor expression and phosphorylation in hippocampal neurons. J. Neuroimmunol. 175, 97-106. doi: 10.1016/j.jneuroim.2006.03.001

Leavitt, V. M., Sumowski, J. F., Chiaravalloti, N., and Deluca, J. (2012). Warmer outdoor temperature is associated with worse cognitive status in multiple sclerosis. Neurology 78, 964-968. doi: 10.1212/WNL.0b013e31824d5834

Lefaucheur, J. P. (2010). Why image-guided navigation becomes essential in the practice of transcranial magnetic stimulation. Neurophysiol. Clin. 40, 1-5. doi: 10.1016/j.neucli.2009.10.004

Lefaucheur, J. P. (2012). Neurophysiology of cortical stimulation. Int. Rev. Neurobiol. 107, 57-85. doi: 10.1016/B978-0-12-404706-8.00005-X

Lefaucheur, J. P., André-Obadia, N., Antal, A., Ayache, S. S., Baeken, C., Benninger, D. H., et al. (2014). Evidence-based guidelines on the therapeutic use of repetitive transcranial magnetic stimulation (rTMS). Clin. Neurophysiol. 125, 2150-2206. doi: 10.1016/j.clinph.2014.05.021

Leocani, L., Colombo, B., Magnani, G., Martinelli-Boneschi, F., Cursi, M., Rossi, P., et al. (2001). Fatigue in multiple sclerosis is associated with abnormal cortical activation to voluntary movement-EEG evidence. Neuroimage 13, 1186-1192. doi: 10.1006/nimg.2001.0759

Lerdal, A., Celius, E. G., Krupp, L., and Dahl, A. A. (2007). A prospective study of patterns of fatigue in multiple sclerosis. Eur. J. Neurol. 14, 1338-1343. doi: 10.1111/j.1468-1331.2007.01974.x

Liebetanz, D., Nitsche, M. A., Tergau, F., and Paulus, W. (2002). Pharmacological approach to the mechanisms of transcranial DC-stimulation-induced after-effects of human motor cortex excitability. Brain 125, 2238-2247. doi: $10.1093 /$ brain/awf238

Lindenberg, R., Nachtigall, L., Meinzer, M., Sieg, M. M., and Flöel, A. (2013). Differential effects of dual and unihemispheric motor cortex stimulation in older adults. J. Neurosci. 33, 9176-9183. doi: 10.1523/JNEUROSCI.005513.2013

Lobentanz, I. S., Asenbaum, S., Vass, K., Sauter, C., Klösch, G., Kollegger, H., et al. (2004). Factors influencing quality of life in multiple sclerosis patients: disability, depressive mood, fatigue and sleep quality. Acta Neurol. Scand. 110, 6-13. doi: 10.1111/j.1600-0404.2004.00257.x

Lu, C., Wei, Y., Hu, R., Wang, Y., Li, K., and Li, X. (2015). Transcranial direct current stimulation ameliorates behavioral deficits and reduces oxidative stress in 1-methyl-4-phenyl-1,2,3,6-tetrahydropyridine-induced mouse model of parkinson's disease. Neuromodulation 18, 442-446; discussion 447. doi: 10.1111/ner.12302

MacAllister, W. S., and Krupp, L. B. (2005). Multiple sclerosis-related fatigue. Phys. Med. Rehabil. Clin. N. Am. 16, 483-502. doi: 10.1016/j.pmr.2005.01.014

Mahad, D., Ziabreva, I., Lassmann, H., and Turnbull, D. (2008). Mitochondrial defects in acute multiple sclerosis lesions. Brain 131, 1722-1735. doi: 10.1093/brain/awn105

Mainero, C., Faroni, J., Gasperini, C., Filippi, M., Giugni, E., Ciccarelli, O., et al. (1999). Fatigue and magnetic resonance imaging activity in multiple sclerosis. J. Neurol. 246, 454-458. doi: 10.1007/s004150050382

Malekzadeh, A., Van de Geer-Peeters, W., De Groot, V., Teunissen, C. E., Beckerman, H., and TREFAMS-ACE Study Group (2015). Fatigue in patients with multiple sclerosis: is it related to pro- and anti-inflammatory cytokines? Dis. Markers 2015:758314. doi: 10.1155/2015/758314

Marrie, R. A., Fisher, E., Miller, D. M., Lee, J. C., and Rudick, R. A. (2005). Association of fatigue and brain atrophy in multiple sclerosis. J. Neurol. Sci. 228, 161-166. doi: 10.1016/j.jns.2004.11.046

Meinzer, M., Antonenko, D., Lindenberg, R., Hetzer, S., Ulm, L., Avirame, K., et al. (2012). Electrical brain stimulation improves cognitive performance by 
modulating functional connectivity and task-specific activation. J. Neurosci. 32, 1859-1866. doi: 10.1523/JNEUROSCI.4812-11.2012

Meinzer, M., Lindenberg, R., Antonenko, D., Flaisch, T., and Flöel, A. (2013). Anodal transcranial direct current stimulation temporarily reverses ageassociated cognitive decline and functional brain activity changes. J. Neurosci. 33, 12470-12478. doi: 10.1523/JNEUROSCI.5743-12.2013

Merkelbach, S., Sittinger, H., and Koenig, J. (2002). Is there a differential impact of fatigue and physical disability on quality of life in multiple sclerosis? J. Nerv. Ment. Dis. 190, 388-393. doi: 10.1097/00005053-200206000-00007

Mills, R. J., and Young, C. A. (2008). A medical definition of fatigue in multiple sclerosis. QJM 101, 49-60. doi: 10.1093/qjmed/hcm122

Mizuno, T., Zhang, G., Takeuchi, H., Kawanokuchi, J., Wang, J., Sonobe, Y., et al. (2008). Interferon-gamma directly induces neurotoxicity through a neuron specific, calcium-permeable complex of IFN-gamma receptor and AMPA GluR1 receptor. FASEB. J. 22, 1797-1806. doi: 10.1096/fj.07-099499

Möller, A., Wiedemann, G., Rohde, U., Backmund, H., and Sonntag, A. (1994). Correlates of cognitive impairment and depressive mood disorder in multiple sclerosis. Acta Psychiatr. Scand. 89, 117-121. doi: 10.1111/j.16000447.1994.tb01497.x

Monte-Silva, K., Kuo, M. F., Thirugnanasambandam, N., Liebetanz, D., Paulus, W., and Nitsche, M. A. (2009). Dose-dependent inverted U-shaped effect of dopamine (D2-like) receptor activation on focal and nonfocal plasticity in humans. J. Neurosci. 29, 6124-6131. doi: 10.1523/JNEUROSCI.0728-09.2009

Monte-Silva, K., Liebetanz, D., Grundey, J., Paulus, W., and Nitsche, M. A. (2010). Dosage-dependent non-linear effect of L-dopa on human motor cortex plasticity. J. Physiol. 588, 3415-3424. doi: 10.1113/jphysiol.2010.190181

Monte-Silva, K., Ruge, D., Teo, J. T., Paulus, W., Rothwell, J. C., and Nitsche, M. A. (2011). D2 receptor block abolishes $\theta$ burst stimulation-induced neuroplasticity in the human motor cortex. Neuropsychopharmacology 36, 2097-2102. doi: 10.1038/npp.2011.100

Mori, F., Codecà, C., Kusayanagi, H., Monteleone, F., Boffa, L., Rimano, A., et al. (2010a). Effects of intermittent theta burst stimulation on spasticity in patients with multiple sclerosis. Eur. J. Neurol. 17, 295-300. doi: 10.1111/j.14681331.2009.02806.x

Mori, F., Codecà, C., Kusayanagi, H., Monteleone, F., Buttari, F., Fiore, S., et al. (2010b). Effects of anodal transcranial direct current stimulation on chronic neuropathic pain in patients with multiple sclerosis. J. Pain 11, 436-442. doi: 10.1016/j.jpain.2009.08.011

Mori, F., Ljoka, C., Magni, E., Codecà, C., Kusayanagi, H., Monteleone, F., et al. (2011). Transcranial magnetic stimulation primes the effects of exercise therapy in multiple sclerosis. J. Neurol. 258, 1281-1287. doi: 10.1007/s00415-0115924-1

Morris, M. E., Cantwell, C., Vowels, L., and Dodd, K. (2002). Changes in gait and fatigue from morning to afternoon in people with multiple sclerosis. J. Neurol. Neurosurg. Psychiatry 72, 361-365. doi: 10.1136/jnnp.72.3.361

Muzio, L., Martino, G., and Furlan, R. (2007). Multifaceted aspects of inflammation in multiple sclerosis: The role of microglia. J. Neuroimmunol. 191, 39-44. doi: 10.1016/j.jneuroim.2007.09.016

Newcombe, J., Uddin, A., Dove, R., Patel, B., Turski, L., Nishizawa, Y., et al. (2008). Glutamate receptor expression in multiple sclerosis lesions. Brain Pathol. 18, 52-61. doi: 10.1111/j.1750-3639.2007.00101.x

Niepel, G., Tench, Ch. R., Morgan, P. S., Evangelou, N., Auer, D. P., and Constantinescu, C. S. (2006). Deep gray matter and fatigue in MS: a T1 relaxation time study. J. Neurol. 253, 896-902. doi: 10.1007/s00415-0060128-9

Nitsche, M. A., Cohen, L. G., Wassermann, E. M., Priori, A., Lang, N., Antal, A., et al. (2008). Transcranial direct current stimulation: State of the art 2008. Brain Stimul. 1, 206-223. doi: 10.1016/j.brs.2008.06.004

Nitsche, M. A., and Fregni, F. (2007). Transcranial direct current stimulation- an adjuvant tool for the treatment of neuropsychiatric disease. Curr. Psychiatry Rev. 3, 222-232. doi: 10.2174/157340007781369649

Nitsche, M. A., Fricke, K., Henschke, U., Schlitterlau, A., Liebetanz, D., Lang, N., et al. (2003). Pharmacological modulation of cortical excitability shifts induced by transcranial direct current stimulation in humans. J. Physiol. 553, 293-301. doi: 10.1113/jphysiol.2003.049916

Nitsche, M. A., Kuo, M. F., Grosch, J., Bergner, C., Monte-Silva, K., and Paulus, W. (2009). D1-receptor impact on neuroplasticity in humans. J. Neurosci. 29, 2648-2653. doi: 10.1523/JNEUROSCI.5366-08.2009
Nitsche, M. A., Lampe, C., Antal, A., Liebetanz, D., Lang, N., Tergau, F., et al. (2006). Dopaminergic modulation of long-lasting direct current-induced cortical excitability changes in the human motor cortex. Eur. J. Neurosci. 23, 1651-1657. doi: 10.1111/j.1460-9568.2006.04676.x

Nitsche, M. A., Monte-Silva, K., Kuo, M. F., and Paulus, W. (2010). Dopaminergic impact on cortical excitability in humans. Rev. Neurosci. 21, 289-298. doi: 10.1515/REVNEURO.2010.21.4.289

Nitsche, M. A., and Paulus, W. (2000). Excitability changes induced in the human motor cortex by weak transcranial direct current stimulation. J. Physiol. 527, 633-639. doi: 10.1111/j.1469-7793.2000.t01-1-00633.x

Nitsche, M. A., and Paulus, W. (2001). Sustained excitability elevations induced by transcranial DC motor cortex stimulation in humans. Neurology 57, 1899-1901. doi: 10.1212/WNL.57.10.1899

Nitsche, M. A., and Paulus, W. (2011). Transcranial direct current stimulationupdate 2011. Restor. Neurol. Neurosci. 29, 463-492. doi: 10.3233/RNN-20110618

Noseworthy, J. H., Lucchinetti, C., Rodriguez, M., and Weinshenker, B. G. (2000). Multiple sclerosis. N. Engl. J. Med. 343, 938-952. doi: 10.1056/NEJM200009283431307

Papadopoulou, A., Müller-Lenke, N., Naegelin, Y., Kalt, G., Bendfeldt, K., Kuster, P., et al. (2013). Contribution of cortical and white matter lesions to cognitive impairment in multiple sclerosis. Mult. Scler. 19, 1290-1296. doi: $10.1177 / 1352458513475490$

Pardini, M., Bonzano, L., Bergamino, M., Bommarito, G., Feraco, P., Murugavel, A., et al. (2015). Cingulum bundle alterations underlie subjective fatigue in multiple sclerosis. Mult. Scler. 21, 442-447. doi: 10.1177/1352458514546791

Pardini, M., Bonzano, L., Mancardi, G. L., and Roccatagliata, L. (2010). Frontal networks play a role in fatigue perception in multiple sclerosis. Behav. Neurosci. 124, 329-336. doi: 10.1037/a0019585

Park, C. H., Chang, W. H., Park, J. Y., Shin, Y. I., Kim, S. T., and Kim, Y. H. (2013). Transcranial direct current stimulation increases resting state interhemispheric connectivity. Neurosci. Lett. 539, 7-10. doi: 10.1016/j.neulet.2013.01.047

Parry, A., Clare, S., Jenkinson, M., Smith, S., Palace, J., and Matthews, P. M. (2002). White matter and lesion T1 relaxation times increase in parallel and correlate with disability in multiple sclerosis. J. Neurol. 249, 1279-1286. doi: 10.1007/s00415-002-0837-7

Pascual-Leone, A., Valls-Solé, J., Wassermann, E. M., and Hallett, M. (1994). Responses to rapid-rate transcranial magnetic stimulation of the human motor cortex. Brain 117, 847-858. doi: 10.1093/brain/117.4.847

Paulus, W., Peterchev, A. V., and Ridding, M. (2013). Transcranial electric and magnetic stimulation: technique and paradigms. Handb. Clin. Neurol. 116, 329-342. doi: 10.1016/B978-0-444-53497-2.00027-9

Pellicano, C., Gallo, A., Li, X., Ikonomidou, V. N., Evangelou, I. E., Ohayon, J. M., et al. (2010). Relationship of cortical atrophy to fatigue in patients with multiple sclerosis. Arch. Neurol. 67, 447-453. doi: 10.1001/archneurol.2010.48

Pittion-Vouyovitch, S., Debouverie, M., Guillemin, F., Vandenberghe, N., Anxionnat, R., and Vespignani, H. (2006). Fatigue in multiple sclerosis is related to disability, depression and quality of life. J. Neurol. Sci. 243, 39-45. doi: 10.1016/j.jns.2005.11.025

Pokryszko-Dragan, A., Frydecka, I., Kosmaczewska, A., Ciszak, L., Bilinska, M., Gruszka, E., et al. (2012). Stimulated peripheral production of interferongamma is related to fatigue and depression in multiple sclerosis. Clin. Neurol. Neurosurg. 114, 1153-1158. doi: 10.1016/j.clineuro.2012.02.048

Polanía, R., Nitsche, M. A., and Paulus, W. (2011b). Modulating functional connectivity patterns and topological functional organization of the human brain with transcranial direct current stimulation. Hum. Brain Mapp. 32, 1236-1249. doi: 10.1002/hbm.21104

Polanía, R., Paulus, W., Antal, A., and Nitsche, M. A. (2011a). Introducing graph theory to track for neuroplastic alterations in the resting human brain: a transcranial direct current stimulation study. Neuroimage 54, 2287-2296. doi: 10.1016/j.neuroimage.2010.09.085

Polanía, R., Paulus, W., and Nitsche, M. A. (2012a). Reorganizing the intrinsic functional architecture of the human primary motor cortex during rest with non-invasive cortical stimulation. PLOS ONE 7:e30971. doi: 10.1371/journal.pone.0030971

Polanía, R., Paulus, W., and Nitsche, M. A. (2012b). Modulating cortico-striatal and thalamo-cortical functional connectivity with transcranial direct current stimulation. Hum. Brain Mapp. 33, 2499-2508. doi: 10.1002/hbm.21380 
Poreisz, C., Boros, K., Antal, A., and Paulus, W. (2007). Safety aspects of transcranial direct current stimulation concerning healthy subjects and patients. Brain Res. Bull. 72, 208-214. doi: 10.1016/j.brainresbull.2007.01.004

Priori, A. (2003). Brain polarization in humans: a reappraisal of an old tool for prolonged non-invasive modulation of brain excitability. Clin. Neurophysiol. 114, 589-595. doi: 10.1016/S1388-2457(02)00437-6

Priori, A., Berardelli, A., Rona, S., Accornero, N., and Manfredi, M. (1998). Polarization of the human motor cortex through the scalp. Neuroreport 9, 2257-2260. doi: 10.1097/00001756-199807130-00020

Provinciali, L., Ceravolo, M. G., Bartolini, M., Logullo, F., and Danni, M. (1999). A multidimensional assessment of multiple sclerosis: relationships between disability domains. Acta Neurol. Scand. 100, 156-162. doi: 10.1111/j.16000404.1999.tb00731.x

Pugliatti, M., Rosati, G., Carton, H., Riise, T., Drulovic, J., Vécsei, L., et al. (2006). The epidemiology of multiple sclerosis in Europe. Eur. J. Neurol. 13, 700-722. doi: 10.1111/j.1468-1331.2006.01342.x

Purpura, D. P., and McMurtry, J. G. (1965). Intracellular activities and evoked potential changes during polarization of motor cortex. J. Neurophysiol. 28, $166-185$.

Redford, E. J., Kapoor, R., and Smith, K. J. (1997). Nitric oxide donors reversibly block axonal conduction: demyelinated axons are especially susceptible. Brain 120, 2149-2157. doi: 10.1093/brain/120.12.2149

Riccitelli, G., Rocca, M. A., Forn, C., Colombo, B., Comi, G., and Filippi, M. (2011). Voxelwise assessment of the regional distribution of damage in the brains of patients with multiple sclerosis and fatigue. Am. J. Neuroradiol. 32, 874-879. doi: 10.3174/ajnr.A2412

Rocca, M. A., Agosta, F., Colombo, B., Mezzapesa, D. M., Falini, A., Comi, G., et al. (2007). fMRI changes in relapsing-remitting multiple sclerosis patients complaining of fatigue after IFNbeta-1a injection. Hum. Brain Mapp. 28, 373-382. doi: 10.1002/hbm.20279

Rocca, M. A., Gatti, R., Agosta, F., Broglia, P., Rossi, P., Riboldi, E., et al. (2009). Influence of task complexity during coordinated hand and foot movements in MS patients with and without fatigue. A kinematic and functional MRI study. J. Neurol. 256, 470-482. doi: 10.1007/s00415-009-0116-y

Rocca, M. A., Parisi, L., Pagani, E., Copetti, M., Rodegher, M., Colombo, B., et al. (2014). Regional but not global brain damage contributes to fatigue in multiple sclerosis. Radiology 273, 511-520. doi: 10.1148/radiol.14140417

Roelcke, U., Kappos, L., Lechner-Scott, J., Brunnschweiler, H., Huber, S., Ammann, W., et al. (1997). Reduced glucose metabolism in the frontal cortex and basal ganglia of multiple sclerosis patients with fatigue: a 18F-fluorodeoxyglucose positron emission tomography study. Neurology 48, 1566-1571. doi: 10.1212/WNL.48.6.1566

Rosso, C., Valabregue, R., Arbizu, C., Ferrieux, S., Vargas, P., Humbert, F., et al. (2014). Connectivity between right inferior frontal gyrus and supplementary motor area predicts after-effects of right frontal cathodal tDCS on picture naming speed. Brain Stimul. 7, 122-129. doi: 10.1016/j.brs.2013.08.007

Rovaris, M., Barnes, D., Woodrofe, N., du Boulay, G. H., Thorpe, J. W., Thompson, A. J., et al. (1996). Patterns of disease activity in multiple sclerosis patients: a study with quantitative gadolinium enhanced brain MRI and cytokine measurement in different clinical subgroups. J. Neurol. 243, 536-542. doi: 10.1007/BF00886876

Rueger, M. A., Keuters, M. H., Walberer, M., Braun, R., Klein, R., Sparing, R., et al. (2012). Multi-session transcranial direct current stimulation (tDCS) elicits inflammatory and regenerative processes in the rat brain. PLoS ONE 7:e43776. doi: 10.1371/journal.pone.0043776

Saiote, C., Goldschmidt, T., Timäus, C., Steenwijk, M. D., Opitz, A., Antal, A., et al. (2014). Impact of transcranial direct current stimulation on fatigue in multiple sclerosis. Restor. Neurol. Neurosci. 32, 423-436. doi: 10.3233/RNN-130372

Sarchielli, P., Greco, L., Floridi, A., Floridi, A., and Gallai, V. (2003). Excitatory amino acids and multiple sclerosis: evidence from cerebrospinal fluid. Arch. Neurol. 60, 1082-1088. doi: 10.1001/archneur.60.8.1082

Schwartz, M., Butovsky, O., Brück, W., and Hanisch, U. K. (2006). Microglial phenotype: is the commitment reversible? Trends Neurosci. 29, 68-74. doi: 10.1016/j.tins.2005.12.005

Sehm, B., Kipping, J., Schäfer, A., Villringer, A., and Ragert, P. (2013). A Comparison between Uni- and Bilateral tDCS effects on functional connectivity of the human motor cortex. Front. Hum. Neurosci. 7:183. doi: 10.3389/fnhum.2013.00183
Sehm, B., Schäfer, A., Kipping, J., Margulies, D., Conde, V., Taubert, M., et al. (2012). Dynamic modulation of intrinsic functional connectivity by transcranial direct current stimulation. J. Neurophysiol. 108, 3253-3263. doi: 10.1152/jn.00606.2012

Sepulcre, J., Masdeu, J. C., Goñi, J., Arrondo, G., Vélez de Mendizábal, N., Bejarano, B., et al. (2009). Fatigue in multiple sclerosis is associated with the disruption of frontal and parietal pathways. Mult. Scler. 15, 337-344. doi: $10.1177 / 1352458508098373$

Sheean, G. L., Murray, N. M., Rothwell, J. C., Miller, D. H., and Thompson, A. J. (1997). An electrophysiological study of the mechanism of fatigue in multiple sclerosis. Brain 120, 299-315. doi: 10.1093/brain/120.2.299

Shrager, P., Custer, A. W., Kazarinova, K., Rasband, M. N., and Mattson, D. (1998). Nerve conduction block by nitric oxide that is mediated by the axonal environment. J. Neurophysiol. 79, 529-536.

Smets, E. M., Garssen, B., Bonke, B., and De Haes, J. C. (1995). The Multidimensional Fatigue Inventory (MFI) psychometric qualities of an instrument to assess fatigue. J. Psychosom. Res. 39, 315-325. doi: 10.1016/00223999(94)00125-O

Specogna, I., Casagrande, F., Lorusso, A., Catalan, M., Gorian, A., Zugna, L., et al. (2012). Functional MRI during the execution of a motor task in patients with multiple sclerosis and fatigue. Radiol. Med. 117, 1398-1407. doi: $10.1007 /$ s11547-012-0845-3

Srinivasan, R., Sailasuta, N., Hurd, R., Nelson, S., and Pelletier, D. (2005). Evidence of elevated glutamate in multiple sclerosis using magnetic resonance spectroscopy at 3T. Brain 128, 1016-1025. doi: 10.1093/brain/ awh467

Stagg, C. J., Bachtiar, V., Amadi, U., Gudberg, C. A., Ilie, A. S., Sampaio-Baptista, C., et al. (2014). Local GABA concentration is related to network-level resting functional connectivity. Elife 3:e01465. doi: 10.7554/eLife.01465

Stagg, C. J., Best, J. G., Stephenson, M. C., O’Shea, J., Wylezinska, M., Kincses, Z. T., et al. (2009). Polarity-sensitive modulation of cortical neurotransmitters by transcranial stimulation. J. Neurosci. 29, 5202-5206. doi: 10.1523/JNEUROSCI.4432-08.2009

Stellwagen, D., Beattie, E. C., Seo, J. Y., and Malenka, R. C. (2005). Differential regulation of AMPA receptor and GABA receptor trafficking by tumor necrosis factor-alpha. J. Neurosci. 25, 3219-3228. doi: 10.1523/JNEUROSCI.448604.2005

Stover, J. F., Lowitzsch, K., and Kempski, O. S. (1997). Cerebrospinal fluid hypoxanthine, xanthine and uric acid levels may reflect glutamate-mediated excitotoxicity in different neurological diseases. Neurosci. Lett. 238, 25-28. doi: 10.1016/S0304-3940(97)00840-9

Stys, P. K. (2005). General mechanisms of axonal damage and its prevention. J. Neurol. Sci. 233, 3-13. doi: 10.1016/j.jns.2005.03.031

Tanaka, T., Takano, Y., Tanaka, S., Hironaka, N., Kobayashi, K., Hanakawa, T., et al. (2013). Transcranial direct-current stimulation increases extracellular dopamine levels in the rat striatum. Front. Syst. Neurosci. 7:6. doi: $10.3389 /$ fnsys.2013.00006

Tartaglia, M. C., Narayanan, S., and Arnold, D. L. (2008). Mental fatigue alters the pattern and increases the volume of cerebral activation required for a motor task in multiple sclerosis patients with fatigue. Eur. J. Neurol. 15, 413-419. doi: 10.1111/j.1468-1331.2008.02090.x

Tartaglia, M. C., Narayanan, S., Francis, S. J., Santos, A. C., De Stefano, N., Lapierre, Y., et al. (2004). The relationship between diffuse axonal damage and fatigue in multiple sclerosis. Arch. Neurol. 61, 201-207. doi: 10.1001/archneur.61. 2.201

Tecchio, F., Cancelli, A., Cottone, C., Zito, G., Pasqualetti, P., Ghazaryan, A., et al. (2014). Multiple sclerosis fatigue relief by bilateral somatosensory cortex neuromodulation. J. Neurol. 261, 1552-1558. doi: 10.1007/s00415-014-7377-9

Tedeschi, G., Dinacci, D., Lavorgna, L., Prinster, A., Savettieri, G., Quattrone, A., et al. (2007). Correlation between fatigue and brain atrophy and lesion load in multiple sclerosis patients independent of disability. J. Neurol. Sci. 263, 15-19. doi: 10.1016/j.jns.2007.07.004

Téllez, N., Alonso, J., Río, J., Tintoré, M., Nos, C., Montalban, X., et al. (2008). The basal ganglia: a substrate for fatigue in multiple sclerosis. Neuroradiology 50, 17-23. doi: 10.1007/s00234-007-0304-3

Vallejo-Illarramendi, A., Domercq, M., Pérez-Cerdá, F., Ravid, R., and Matute, C. (2006). Increased expression and function of glutamate transporters in multiple sclerosis. Neurobiol. Dis. 21, 154-164. doi: 10.1016/j.nbd.2005.06.017 
van der Werf, S. P., Jongen, P. J., Lycklama à Nijeholt, G. J., Barkhof, F., Hommes, O. R., and Bleijenberg, G. (1998). Fatigue in multiple sclerosis: interrelations between fatigue complaints, cerebral MRI abnormalities and neurological disability. J. Neurol. Sci. 160, 164-170. doi: 10.1016/S0022-510X(98) 00251-2

Vucic, S., Burke, D., and Kiernan, M. C. (2010). Fatigue in multiple sclerosis: Mechanisms and management. Clin. Neurophysiol. 121, 809-817. doi: 10.1016/j.clinph.2009.12.013

Waxman, S. G. (2006). Axonal conduction and injury in multiple sclerosis: the role of sodium channels. Nat. Rev. Neurosci. 7, 932-941. doi: 10.1038/nrn2023

Wessely, S. (1998). The epidemiology of chronic fatigue syndrome. Epidemiol. Psichiatr. Soc. 7, 10-24. doi: 10.1017/S1121189X 00007089

Wingerchuk, D. M., and Carter, J. L. (2014). Multiple sclerosis: current and emerging disease-modifying therapies and treatment strategies. Mayo Clin. Proc. 89, 225-240. doi: 10.1016/j.mayocp.2013.11.002

Yaldizli, Ö., Glassl, S., Sturm, D., Papadopoulou, A., Gass, A., Tettenborn, B., et al. (2011). Fatigue and progression of corpus callosum atrophy in multiple sclerosis. J. Neurol. 258, 2199-2205. doi: 10.1007/s00415-0116091-0

Yaldizli, Ö., Penner, I. K., Frontzek, K., Naegelin, Y., Amann, M., Papadopoulou, A., et al. (2014). The relationship between total and regional corpus callosum atrophy, cognitive impairment and fatigue in multiple sclerosis patients. Mult. Scler. 20, 356-364. doi: 10.1177/1352458513496880
Zago, S., Ferrucci, R., Fregni, F., and Priori, A. (2008). Bartholow, Sciamanna, Alberti: pioneers in the electrical stimulation of the exposed human cerebral cortex. Neuroscientist 14, 521-528. doi: 10.1177/1073858407311101

Zellini, F., Niepel, G., Tench, C. R., and Constantinescu, C. S. (2009). Hypothalamic involvement assessed by $\mathrm{T} 1$ relaxation time in patients with relapsing-remitting multiple sclerosis. Mult. Scler. 15, 1442-1449. doi: $10.1177 / 1352458509350306$

Zwarts, M. J., Bleijenberg, G., and van Engelen, B. G. (2008). Clinical neurophysiology of fatigue. Clin. Neurophysiol. 119, 2-10. doi: 10.1016/j.clinph.2007.09.126

Conflict of Interest Statement: MAC, SSA, NR, RA and JPL declare that the research was conducted in the absence of any commercial or financial relationships that could be construed as a potential conflict of interest. AC gave expert testimony for CSL Behring, Novartis, received grants from Biogen, Novartis, CSL Behring, GE Neuro, Octapharma, and gave lectures for Genzyme.

Copyright (c) 2015 Chalah, Riachi, Ahdab, Créange, Lefaucheur and Ayache. This is an open-access article distributed under the terms of the Creative Commons Attribution License (CC BY). The use, distribution or reproduction in other forums is permitted, provided the original author(s) or licensor are credited and that the original publication in this journal is cited, in accordance with accepted academic practice. No use, distribution or reproduction is permitted which does not comply with these terms. 